\title{
The Soluble Form of LOTUS inhibits Nogo Receptor-Mediated Signaling by Interfering with the Interaction Between Nogo Receptor Type 1 and p75 Neurotrophin Receptor
}

\author{
다aka Kawakami, ${ }^{1}$ Yuji Kurihara, ${ }^{1}$ Yu Saito, ${ }^{1}$ Yuki Fujita, ${ }^{2}$-Toshihide Yamashita, ${ }^{2}$ and Kohtaro Takei ${ }^{1}$ \\ ${ }^{1}$ Molecular Medical Bioscience Laboratory, Department of Medical Life Science, Yokohama City University Graduate School of Medical Life Science, \\ Yokohama 230-0045, Japan and 2Department of Molecular Neuroscience, Osaka University Graduate School of Medicine, Suita 565-0871, Japan
}

\begin{abstract}
Nogo receptor type 1 (NgR1) is known to inhibit neuronal regeneration in the CNS. Previously, we have shown that lateral olfactory tract usher substance (LOTUS) interacts with NgR1 and inhibits its function by blocking its ligand binding. Therefore, LOTUS is expected to have therapeutic potential for the promotion of neuronal regeneration. However, it remains unknown whether the soluble form of LOTUS (s-LOTUS) also has an inhibitory action on NgR1 function as a candidate for therapeutic agents. Here, we show that s-LOTUS inhibits NgR1-mediated signaling by inhibiting the molecular interaction between $\mathrm{NgR} 1$ and its coreceptor, $\mathrm{p} 75$ neurotrophin receptor $\left(\mathrm{p} 75^{\mathrm{NTR}}\right)$. In contrast to the membrane-bound form of LOTUS, s-LOTUS did not block ligand binding to NgR1. However, we identified p $75^{\text {NTR }}$ as a novel LOTUS binding partner and found that s-LOTUS suppressed the interaction between $\mathrm{p} 75^{\mathrm{NTR}}$ and NgR1. s-LOTUS inhibited myelinassociated inhibitor (MAI)-induced RhoA activation in murine cortical neurons. Functional analyses revealed that s-LOTUS inhibited MAI-induced growth cone collapse and neurite outgrowth inhibition in chick DRG neurons. In addition, whereas olfactory bulb neurons of lotus-KO mice are sensitive to MAI due to a lack of LOTUS expression, treatment with s-LOTUS inhibited MAI-induced growth cone collapse in these neurons. Finally, we observed that s-LOTUS promoted axonal regeneration in optic nerve crush injury of mice (either sex). These findings suggest that s-LOTUS inhibits NgR1-mediated signaling, possibly by interfering with the interaction between NgR1 and $\mathrm{p} 75^{\mathrm{NTR}}$. Therefore, s-LOTUS may have potential as a therapeutic agent for neuronal regeneration in the damaged CNS.
\end{abstract}

Key words: antagonist; LOTUS; Nogo receptor; regeneration

\section{Significance Statement}

Nogo receptor type $1(\mathrm{NgR} 1)$ is a receptor well known to inhibit neuronal regeneration in the CNS. Because the membrane-bound form of lateral olfactory tract usher substance (LOTUS) antagonizes NgR1 through a cis-type molecular interaction between LOTUS and NgR1, the soluble form of LOTUS (s-LOTUS) is expected to be a therapeutic agent for neuronal regeneration. In our present study, we show that s-LOTUS inhibits the interaction between $\mathrm{NgR} 1$ and $\mathrm{p} 75^{\mathrm{NTR}}, \mathrm{NgR} 1$ ligand-induced RhoA activation, growth cone collapse, and neurite outgrowth inhibition and promotes axonal regeneration. Our results indicate that s-LOTUS inhibits NgR1-mediated signaling through a trans-type molecular interaction between LOTUS and NgR1 and, therefore, s-LOTUS may have therapeutic potential for neuronal regeneration.

\section{Introduction}

CNS injuries such as traumatic brain injury and spinal cord injury cause devastating sequelae in patients for the rest of their

Received April 9, 2017; revised Jan. 12, 2018; accepted Jan. 17, 2018.

Author contributions: Y. Kawakami, Y. Kurihara, and K.T. designed research; Y. Kawakami and Y.S. performed research;Y.F. and T.Y. contributed unpublished reagents/analytic tools; Y. Kawakami, Y. Kurihara, and K.T. analyzed data; Y. Kawakami, Y. Kurihara, and K.T. wrote the paper.

This work was supported by a Grant-in-Aid from The Ministry of Education, Culture, Sports, Science and Technology of Japan (K.T.) and the Yokohama Foundation for Advancement of Medical Science (Y. Kawakami). We thank Dr. Stephen M. Strittmatter at Yale University for the kind gift of 6His-AP-0Mgp plasmid, Drs. Toru Takahashi and Tomoko Satake at Yokohama City University for skillful technical assistance with the optic nerve crush injury, Dr. Masumi Iketani at Tokyo Metropolitan Institute of Gerontology for skillful technical assistance with the primary culture of $\mathrm{OB}$ neurons, Ms. Eriko Saito at Yokohama City University for the support with genotyping, and Dr. Yukio Sasaki at Yokohama City University for helpful advice on cell culture of primary cortical neurons. lives. Several molecules expressed in neurons and glial cells trigger the intracellular signaling that gives raise to the failure to regenerate (Niclou et al., 2006; Yiu and He, 2006; Schwab, 2010). $\mathrm{NgR} 1$ is known to be one of the main inhibitory factors of neuronal regeneration and a common receptor of MAIs [Nogo-A (GrandPré et al., 2000; Fournier et al., 2001), myelin-associated glycoprotein (MAG) (Liu et al., 2002), and oligodendrocyte my-

\footnotetext{
The authors declare no competing financial interests.
}

Correspondence should be addressed to Kohtaro Takei, Molecular Medical Bioscience Laboratory, Department of Medical Life Science, Yokohama City University Graduate School of Medical Life Science, Suehiro-cho 1-7-29, Tsurumi Ward, Yokohama 230-0045, Japan. E-mail: kohtaro@med.yokohama-cu.ac.jp. DOl:10.1523/JNEUROSCI.0953-17.2018

Copyright $\odot 2018$ the authors $\quad 0270-6474 / 18 / 382589-16 \$ 15.00 / 0$ 
elin glycoprotein (OMgp) (Wang et al., 2002b)], B lymphocyte stimulator (BLyS) (Zhang et al., 2009), and chondroitin sulfate proteoglycans (CSPGs) (Dickendesher et al., 2012). The binding of these molecules to $\mathrm{NgR} 1$ is the start point of the signaling and the interaction of NgR1 with its coreceptors $\mathrm{p} 75^{\mathrm{NTR}}$ and leucinerich repeat and Ig domain-containing Nogo receptor-interacting protein 1 (LINGO-1) is essential for signal transduction due to the lack of an intracellular domain of NgR1 (Wang et al., 2002a; Mi et al., 2004). Signal transduction via this complex results in growth cone collapse and neurite outgrowth inhibition through activation of the small GTPase Rho (Fournier et al., 2003; Mi et al., 2004; Yiu and He, 2006). Many studies have demonstrated that counteracting Nogo-A (Bregman et al., 1995), NgR1 (GrandPré et al., 2002; Fischer et al., 2004), and RhoA activation (Fournier et al., 2003; Yamashita and Tohyama, 2003) promotes neuronal regeneration. Therefore, NgR1-mediated signaling is expected to be a therapeutic target for neuronal regeneration in the damaged CNS.

Previously, we have identified lateral olfactory tract usher substance (LOTUS), a splicing variant of cartilage acidic protein-1 gene (Crtac1), as an endogenous antagonist for NgR1 (Sato et al., 2011; Kurihara et al., 2014). We also found that the membranebound form of LOTUS interacts with NgR1 through cis-type binding and blocks the binding of MAIs to NgR1, resulting in the suppression of growth cone collapse and neurite outgrowth inhibition induced by MAIs (Sato et al., 2011; Kurihara et al., 2014). Therefore, s-LOTUS is expected to be a potent therapeutic agent for neuronal regeneration after injury in the CNS. However, whether s-LOTUS also exerts inhibitory activity on NgR1 through trans-type binding has not yet been determined.

In this study, we show that $\mathrm{p} 75^{\mathrm{NTR}}$ is a novel LOTUS-binding protein and that s-LOTUS inhibits NgR1-mediated signaling, possibly by interfering with the molecular interaction between NgR1 and p $75^{\mathrm{NTR}}$. Moreover, s-LOTUS suppressed MAI-induced growth cone collapse and neurite outgrowth inhibition and promoted axonal regeneration in an optic nerve crush injury. The data suggest that s-LOTUS may work as a therapeutic agent for neuronal regeneration in the injured CNS.

\section{Materials and Methods}

Animals. Fertilized White Leghorn eggs were purchased from Yamagishi and incubated at $37^{\circ} \mathrm{C}$ in a standard egg incubator. WT C57BL/6 J mice (RRID:IMSR_JAX: 000664) were purchased from Japan SLC. The lotus mutant mice were generated as described previously (Sato et al., 2011) and were housed in a specific-pathogen-free facility with ad libitum access to autoclaved water and food. Genotypes of the offspring of the mutant mice were assessed with PCR using the following primer sequences to target the intronic region of the mouse lotus locus (forward: 5'-TAG CTC TTC TCC CGG GAA GC-3' , reverse: 5' -CTT GCA CCC ATC CCA GAA GG-3') or the genomic region containing the neomycin gene (forward: 5'-GGA TTC ATC GAC TGT GGC CG-3').

Throughout the experimental procedures, all efforts were made to minimize the number of animals used and their suffering. The procedures were approved by the institutional animal care and use ethics committee of Yokohama City University (approval number: T13-001, T13-009, T-A-15001, T-A-16-002).

Construction of expression plasmids. The plasmids encoding 6His tagand alkaline phosphatase (AP) tag-fused Nogo66 (6His-AP-Nogo66), which is an NgR1-binding domain and an axonal growth inhibitory domain of Nogo-A (GrandPré et al., 2000) or the extracellular domain of mouse MAG fusing AP tag and 6His tag (MAG-AP-6His) were generated as described previously (Sato et al., 2011; Kurihara et al., 2014). The plasmid encoding 6His tag- and AP tag-fused glycosylphosphatidylinositol (GPI)-anchored site-deleted human OMgp (AP-OMgp) was provided by Stephen M. Strittmatter (Barton et al., 2003; Li et al., 2004). The plasmids encoding full-length mouse LOTUS or mouse NgR1 were gen- erated as described previously (Sato et al., 2011). The mouse p75 ${ }^{\text {NTR }}$ cDNA was amplified by PCR from a mouse adult brain cDNA template and cloned into a mammalian expression vector. The transmembrane region-deleted mouse LOTUS fusing mutated human Fc tag constructed to reduce antibody-dependent cellular cytotoxicity and complementdependent cytotoxicity followed by 6 His tag (LOTUS-Fc-6His), streptavidin-binding peptide (SBP) tag- and the above human Fc tag-fused mouse LOTUS without its transmembrane region (SBP-Fc-LOTUS), SBP tag- and FLAG tag-fused mouse LOTUS (SBP-FLAG-LOTUS), GPIlinkage region-deleted mouse NgR1 (Fournier et al., 2001) fusing the above human Fc tag and SBP tag (NgR1-Fc-SBP), the SBP tag- and the above human $F_{c}$ tag-fused ectodomain of mouse p $75^{\text {NTR }}$ (SBP-Fcp75 ${ }^{\mathrm{NTR}}$ ), GST tag-fused p $75^{\mathrm{NTR}}$ (GST-p75 ${ }^{\mathrm{NTR}}$ ), and the SBP tag- and AP tag-fused ectodomain of mouse MAG (SBP-AP-MAG) were constructed by standard PCR cloning using the KOD DNA polymerase (TOYOBO). All fragments inserted in each plasmid were confirmed by DNA sequencing. The accession numbers of these mRNAs are described as follows: mouse LOTUS (NM_145123), mouse p75 ${ }^{\text {NTR }}$ (NM_033217), mouse NgR1 (NM_022982), mouse Nogo-A (NM_194054), mouse MAG (NM_010758), and human OMgp (NM_002544).

Cell culture. Cos-7 cells (RRID:CVCL_0024) and HEK293T (RRID: CVCL_0063) cells were cultured in DMEM (4.5 g/L glucose with L-glutamine and sodium pyruvate; Nacalai Tesque) containing 10\% FBS (Biological Industries) and $0.5 \%$ penicillin-streptomycin mixed solution (Nacalai Tesque). For cell culture, all of the cells were manipulated with sterile technique and incubated at $37^{\circ} \mathrm{C}$ with $5 \% \mathrm{CO}_{2}$.

Protein purification. The plasmids $(0.35 \mu \mathrm{g} / \mathrm{ml})$ encoding the SBP tag or $6 \mathrm{His}$ tag sequences were transfected with polyethylenimine Max ( $2 \mu \mathrm{g} / \mathrm{ml}$; Polysciences) into HEK293T cells and cells were incubated for $4 \mathrm{~d}$. Cell culture medium was centrifuged at $117,000 \times g$ for $1 \mathrm{~h}$. SBPtagged protein was collected from the culture medium using high capacity streptavidin agarose resin (Thermo Fisher Scientific, catalog \#20361) and eluted with PBS containing $2 \mathrm{~mm}$ biotin. The centrifuged supernatant of the culture medium containing 6 His-tagged protein was dialyzed

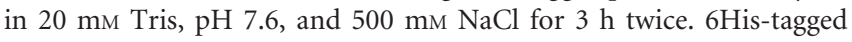
protein was adsorbed to Talon metal affinity resin (Clontech, catalog \#635502) and eluted with the above dialysis solution containing $50 \mathrm{~mm}$ imidazole.

AP-fused protein was added to $p$-nitrophenyl phosphate ( $p$ NPP) (Sigma-Aldrich) and quantified by measuring the absorbance at $405 \mathrm{~nm}$ with a microplate reader (Bio-Rad). For non-AP-fused protein, the eluted proteins were prepared with $4 \times$ Laemmli buffer ( $40 \%$ glycerol, $8 \%$ SDS, 250 mm Tris, pH 6.8, and $0.06 \%$ bromophenol blue), loaded onto a $10 \%$ acrylamide gel containing $0.27 \%$ bis-acrylamide, separated with SDS-PAGE, and stained with Coomassie brilliant blue. The intensity of the stained protein was measured as the concentration of the protein using ImageQuant LAS 4000 Mini (GE Healthcare).

Binding assay. The binding assay was performed as described previously (Sato et al., 2011; Kurihara et al., 2014). Briefly, Cos-7 cells were plated onto 24-well plates (Greiner Bio-One, catalog \#662160) at a density of $5 \times 10^{4}$ cells per well. The plasmids $(0.2 \mu \mathrm{g}$ per well) encoding p75 ${ }^{\text {NTR }}$, NgR1, or LOTUS were transfected using Fugene 6 (Promega) and cultured for $48 \mathrm{~h}$. The cultured cells were treated with a protein diluted with culture medium and incubated for $1 \mathrm{~h}$ at $37^{\circ} \mathrm{C}$ with $5 \% \mathrm{CO}_{2}$. After treatment, the cells were fixed with 4\% PFA in PBS containing $2 \mathrm{~mm}$ $\mathrm{MgCl}_{2}$ for $1 \mathrm{~h}$ at room temperature (RT), washed with PBS containing 2 $\mathrm{mm} \mathrm{MgCl}$, and incubated for $1 \mathrm{~h}$ at $67^{\circ} \mathrm{C}$ to inactivate endogenous AP. After blocking with $5 \%$ skim milk diluted with TBS containing $0.1 \%$ Tween 20 (TBST) for $1 \mathrm{~h}$ at RT, anti-SBP antibody ( $40 \mathrm{ng} / \mathrm{ml}$; Santa Cruz Biotechnology, RRID:AB_1128239) was applied and cells were incubated for $1 \mathrm{~h}$ at RT. After washing with TBST four times, biotinylated antimouse IgG antibody $(0.7 \mu \mathrm{g} / \mathrm{ml}$; Jackson ImmunoResearch Laboratories, catalog \#115-065-003, RRID:AB_2338557) was applied and cells were incubated for $1 \mathrm{~h}$ at RT. Next, AP-conjugated avidin-biotin complex from a kit (1:5000 dilution; Vector Laboratories) was applied and cells were incubated for $1 \mathrm{~h}$ at RT. For photographs, 5-bromo-4-chloro3-indolyl phosphate $(35 \mu \mathrm{g} / \mathrm{ml})$ and nitroblue tetrazolium chloride (90 $\mu \mathrm{g} / \mathrm{ml}$ ) (both Roche) were applied as substrates of AP and cells were incubated at RT. After the reaction was stopped and washed with TBST, 
photographs were taken with an Eclipse Ti microscope (Nikon) equipped with a $10 \times$ objective lens (Plan Fluor; Nikon) and an EMCCD camera (iXon3 860; Andor Technology) using NICE elements software (Nikon). Fluorescent images were analyzed with Photoshop (Adobe Systems, RRID:SCR_014199).

For quantification, $1 \mathrm{mg} / \mathrm{ml} \mathrm{pNPP}$ was applied and cells were incubated at RT. One hundred microliters of supernatant was transferred to a 96-well plate (Greiner Bio-One, catalog \#655101), and the absorbance at $405 \mathrm{~nm}$ was measured with a microplate reader (Bio-Rad). Each sample was tested in duplicate.

For the confirmation of protein overexpression on the cell surface, the transfected cells were treated with each primary antibody diluted with culture medium (p75 ${ }^{\mathrm{NTR}}, 1: 1000$; Abcam, catalog \#ab8874, RRID: AB_306827; NgR1, $0.2 \mu \mathrm{g} / \mathrm{ml}$; R\&D Systems, catalog \#AF1440, RRID: AB_2183731; LOTUS, $1 \mu \mathrm{g} / \mathrm{ml}$, purified as described previously; Sato et al., 2011) and incubated for $1 \mathrm{~h}$ at $37^{\circ} \mathrm{C}$ with $5 \% \mathrm{CO}_{2}$. After fixation with $4 \%$ PFA in PBS for $1 \mathrm{~h}$ at RT, the cells were washed with TBST three times and treated with each secondary antibody conjugated with Alexa Fluor 488 (anti-rabbit IgG, $0.75 \mu \mathrm{g} / \mathrm{ml}$; Jackson ImmunoResearch Laboratories, catalog \#111-545-003, RRID:AB_2338046; anti-goat IgG, $0.75 \mu \mathrm{g} / \mathrm{ml}$; Jackson ImmunoResearch Laboratories, catalog \#705-545-003, RRID:AB_2340428; and anti-hamster IgG, $0.75 \mu \mathrm{g} / \mathrm{ml}$; Jackson ImmunoResearch Laboratories, catalog \#127-545-099, RRID:AB_2338996) for $1 \mathrm{~h}$ at RT. Photographs were taken with an Eclipse Ti microscope (Nikon).

For binding assay of s-LOTUS for endogenous $\mathrm{p} 75^{\mathrm{NTR}}$ in OB neurons of WT mice, SBP-Fc-LOTUS ( $1 \mu \mathrm{M})$ or SBP-Fc (control) diluted with the culture medium was applied and incubated for $1 \mathrm{~h}$ at $37^{\circ} \mathrm{C}$ with $5 \% \mathrm{CO}_{2}$. After fixation with $4 \%$ PFA for $10 \mathrm{~min}$ at $37^{\circ} \mathrm{C}$ and sequentially for 10 min at RT, OB neurons were treated with primary antibodies for $\mathrm{p} 75^{\mathrm{NTR}}$ (1:100; Abcam, RRID:AB_306827) and SBP $(0.2 \mu \mathrm{g} / \mathrm{ml}$; Santa Cruz Biotechnology, RRID:AB_1128239) diluted with PBS for $1 \mathrm{~h}$ at RT, and sequentially with biotinylated antibody $(0.7 \mu \mathrm{g} / \mathrm{ml}$; Jackson ImmunoResearch Laboratories, RRID:AB_2338557) for anti-SBP antibody and secondary antibody for p75NTR conjugated with Alexa Fluor $594(1.5 \mu \mathrm{g} /$ $\mathrm{ml}$; Jackson ImmunoResearch Laboratories, RRID:AB_2338046) for $1 \mathrm{~h}$ at RT in the dark. After wash with PBS containing 0.05\% Tween 20 (PBST), FITC-conjugated avidin D ( $5 \mu \mathrm{g} / \mathrm{ml}$; Vector Laboratories cata$\log$ \#A-2011, RRID:AB_2336456) diluted with PBS was applied for 30 min at RT in the dark. Photographs were taken with TCS SP8 (Leica, RRID:SCR_008960).

Proximity ligation assay (PLA). Cos-7 cells were plated on poly-L-lysine (PLL, $100 \mu \mathrm{g} / \mathrm{ml}$; Wako)-coated chamber slide (Thermo Fisher Scientific, catalog \#177445) at a density of $3 \times 10^{4}$ cells per well. The plasmids encoding GST-p $75^{\mathrm{NTR}}$ or SBP-FLAG-LOTUS were transfected in the same way as in the binding assay described above. After $48 \mathrm{~h}$ of incubation, antibodies for detecting SBP $(0.2 \mu \mathrm{g} / \mathrm{ml}$; Santa Cruz Biotechnology, catalog \#sc-101595) or GST ( $1 \mu \mathrm{g} / \mathrm{ml}$; Abcam, catalog \#ab9085, RRID: AB_306993) or control IgG $(0.2 \mu \mathrm{g} / \mathrm{ml}$; Rockland Immunochemicals, catalog \#010-0102; $0.2 \mu \mathrm{g} / \mathrm{ml}$; Jackson ImmunoResearch Laboratories, catalog \#011-000-003) were applied and cells were incubated for $1 \mathrm{~h}$ at $37^{\circ} \mathrm{C}$. After the cells were fixed with $4 \%$ PFA in PBS for $1 \mathrm{~h}$ at RT and washed with TBST, PLA was performed with the Duolink In Situ Detection Reagents Orange (Sigma-Aldrich, catalog \#DUO92007) according to the manufacturer's instructions. Briefly, after PLA probes of antimouse MINUS (catalog \#DUO92004) and anti-rabbit PLUS (catalog \#DUO92002) were applied and incubated for $1 \mathrm{~h}$ at $37^{\circ} \mathrm{C}$, ligase and polymerase were applied and cells were incubated at $37^{\circ} \mathrm{C}$ for $30 \mathrm{~min}$ and $100 \mathrm{~min}$, respectively. Photographs were taken with a BZ-8100 microscope (Keyence).

ELISA. To determine the binding affinity of LOTUS for $\mathrm{p} 75^{\mathrm{NTR}}$, purified SBP-Fc-p75 ${ }^{\mathrm{NTR}}$ was diluted to $0.5 \mu \mathrm{g} / \mathrm{ml}$ with PBS containing $2.5 \%$ skim milk and was plated on an ELISA plate (Nunc-Immuno Plate; Thermo Fisher Scientific, catalog \#446612) overnight at RT. Each well was washed three times with PBST and treated with soluble LOTUS-Fc$6 \mathrm{His}$ or Fc-6His diluted with PBS containing $2.5 \%$ skim milk at each concentration for $90 \mathrm{~min}$ at $37^{\circ} \mathrm{C}$. After washing 4 times with PBST, anti-His-tag antibody $(0.25 \mu \mathrm{g} / \mathrm{ml}$; MBL, Aichi, catalog \#D291-3, RRID: AB_10597733) or control IgG $(0.25 \mu \mathrm{g} / \mathrm{ml}$; Rockland Immunochemicals, catalog \#010-0102, RRID:AB_840785) was applied and cells were incubated for $90 \mathrm{~min}$ at RT. Each well was washed four times with PBST and incubated with HRP-conjugated secondary antibody (1:10,000, GE Healthcare, catalog \#NA931, RRID:AB_772210) for 90 min at RT. After washing four times with PBST, $100 \mu$ l of HRP substrate (Substrate Reagent Pack; R\&D Systems, catalog \#DY999) was applied and cells were incubated for $20 \mathrm{~min}$ at RT in the dark; the reaction was stopped with an equivalent amount of $1 \mathrm{M} \mathrm{HCl}$. Absorbance at 450 and $570 \mathrm{~nm}$ as a reference was measured with a microplate reader (Bio-Rad). Each sample was tested in duplicate.

Pull-down assay. Cos-7 or HEK293T cells were plated on 6-well plates (Greiner Bio-One, catalog \#657160) at a density of $5 \times 10^{5}$ cells per well and cultured for $24 \mathrm{~h}$. The plasmids encoding GST-p $75^{\mathrm{NTR}}, \mathrm{NgR} 1$, and/or SBP-FLAG-LOTUS (2.0 $\mu$ g per well, in total) were transfected with Fugene 6 (Roche). After $72 \mathrm{~h}$ in culture, the cells were transferred on ice and washed with cold PBS once; treated with lysis buffer containing $20 \mathrm{~mm}$ Tris, pH 7.5, $150 \mathrm{~mm} \mathrm{NaCl}, 1 \%$ Nonidet P-40, $10 \mathrm{~mm}$ $\mathrm{NaF}, 1 \mathrm{~mm}$ sodium orthovanadate (Sigma-Aldrich), $10 \mu \mathrm{g} / \mathrm{ml}$ leupeptin (Nacalai Tesque), $0.1 \mathrm{U} / \mathrm{ml}$ aprotinin (Sigma-Aldrich), and $50 \mu \mathrm{M}$ p-amidinophenyl-methylsufonyl fluoride (Nacalai Tesque); scraped; and incubated for $10 \mathrm{~min}$ at $4^{\circ} \mathrm{C}$ with mild rotation. After centrifugation at $16,900 \times g$ for $10 \mathrm{~min}$, the supernatant was incubated with glutathione Sepharose beads ( $10 \mu \mathrm{l}$ per sample; GE Healthcare, catalog \#17-0756-01) and incubated for $4 \mathrm{~h}$ at $4^{\circ} \mathrm{C}$ with mild rotation. For s-LOTUS treatment, the transfected cells were treated with SBP-Fc-LOTUS $(1 \mu \mathrm{M})$ or its vehicle (control) diluted with culture medium and incubated for $30 \mathrm{~min}$ at $37^{\circ} \mathrm{C}$ with $5 \% \mathrm{CO}_{2}$. After cell lysate was prepared, SBP-Fc-LOTUS or its vehicle was applied to the cell lysate at a concentration of $1 \mu \mathrm{M}$ with glutathione Sepharose beads and the mixture was incubated for $4 \mathrm{~h}$ at $4^{\circ} \mathrm{C}$. The beads were washed with the lysis buffer four times, suspended with $4 \times$ Laemmli buffer, and boiled for $7 \mathrm{~min}$ at $100^{\circ} \mathrm{C}$.

RhoA pull-down assay. Cortical neurons of embryonic day 18.5 (E18.5) WT mice were of either sex dissociated with $0.25 \%$ trypsin (Invitrogen, catalog \#15090-046) and cultured on PLL (100 $\mu \mathrm{g} / \mathrm{ml}$, Wako)-coated dishes in DMEM/Ham's F-12 (Sigma-Aldrich) containing 10\% FBS (Biological Industries). After $16 \mathrm{~h}$, the medium was exchanged to DMEM/ Ham's F-12 containing 2\% B27 supplement (Invitrogen, catalog \#17504044). After $73 \mathrm{~h}$ of cell culture, the cells were treated with SBP-Fc-LOTUS or SBP-Fc at a concentration of $1 \mu \mathrm{M}$ for $30 \mathrm{~min}$ at $37^{\circ} \mathrm{C}$ with $5 \% \mathrm{CO}_{2}$. Then, Nogo66-Fc (200 nm; R\&D Systems, catalog \#3728-NG) or PBS was applied for $30 \mathrm{~min}$ at $37^{\circ} \mathrm{C}$ with $5 \% \mathrm{CO}_{2}$. For treatment with MAG, MAG-Fc ( $25 \mu \mathrm{g} / \mathrm{ml}$; R\&D Systems, catalog \#538-MG) or PBS was applied for $15 \mathrm{~min}$ at $37^{\circ} \mathrm{C}$ with $5 \% \mathrm{CO}_{2}$. The treated cells were washed with cold TBS once and treated with Rho lysis buffer containing $50 \mathrm{~mm}$ Tris, $\mathrm{pH}$ 7.5, $150 \mathrm{~mm} \mathrm{NaCl}, 30 \mathrm{~mm} \mathrm{MgCl}_{2}, 1 \%$ Nonidet P-40, 1 mm sodium orthovanadate (Sigma-Aldrich), $10 \mathrm{~mm} \mathrm{NaF}, 1 \mathrm{~mm}$ DTT, $10 \mu \mathrm{g} / \mathrm{ml} \mathrm{leu-}$ peptin (Nacalai Tesque), and $0.1 \mathrm{U} / \mathrm{ml}$ aprotinin (Sigma-Aldrich). After centrifugation at $16,900 \times g$ for 10 min, cell lysate was incubated with GST-fused Rhotekin-Rho binding domain beads (Cytoskeleton, catalog \#RT02) for $45 \mathrm{~min}$ at $4^{\circ} \mathrm{C}$ with mild rotation. The beads were washed twice with Rho lysis buffer, suspended in the same volume of $2 \times$ Laemmli buffer (20\% glycerol, 4\% SDS, $125 \mathrm{~mm}$ Tris, $\mathrm{pH} 6.8$, and $0.03 \%$ bromophenol blue), and boiled for $7 \mathrm{~min}$ at $100^{\circ} \mathrm{C}$.

Immunoprecipitation. Cerebellar granule neurons from $\mathrm{P} 7$ lotus-KO mice of either sex were plated on a PLL-coated cell culture dish, and incubated overnight at $37^{\circ} \mathrm{C}$ with $5 \% \mathrm{CO}_{2}$. The cells were treated with SBP-FLAG-tagged-LOTUS or SBP-AP protein $(1 \mu \mathrm{M})$ for $30 \mathrm{~min}$ and samples were then prepared with the same lysis buffer and in the same manner as that used in the pull-down assay. The cell lysate was incubated with anti-p75NTR antibody ( $4 \mu \mathrm{g} / \mathrm{ml}$; Promega, catalog \#G3231, RRID: AB_430853G3231) or control IgG ( $4 \mu \mathrm{g} / \mathrm{ml}$; Jackson ImmunoResearch Laboratories, catalog \#011-000-003, RRID:AB_2337118) overnight at $4^{\circ} \mathrm{C}$. Protein A Sepharose beads (GE Healthcare) were washed with PBS and incubated with $1 \%$ gelatin for $1 \mathrm{~h}$ at RT for blocking and the cell lysate was subsequently incubated with the beads for $3 \mathrm{~h}$ at $4^{\circ} \mathrm{C}$. The beads were washed $4 \times$ with the lysis buffer, suspended in $4 \times$ Laemmli buffer, and boiled for $7 \mathrm{~min}$ at $100^{\circ} \mathrm{C}$.

Western blotting. The samples were loaded onto $10-12.5 \%$ acrylamide gels and separated with SDS-PAGE. The protein was transferred to a polyvinylidene difluoride membrane (Immobilon-P Transfer Mem- 
brane; Merck Millipore) by semidry blotting for $1 \mathrm{~h}$. The membrane surface was blocked with 5\% skim milk in TBST for $1 \mathrm{~h}$ at RT with constant agitation and incubated with primary antibody for $1-2 \mathrm{~h}$ at RT with constant agitation $(\mathrm{NgR} 1,0.1 \mu \mathrm{g} / \mathrm{ml}$; R\&D Systems, catalog \#AF1440, RRID:AB_2183731; p75 ${ }^{\text {NTR }}, 0.2 \mu \mathrm{g} / \mathrm{ml}$; Promega, catalog \#G3231, RRID: AB_430853; $\beta$ actin, $0.18 \mu \mathrm{g} / \mathrm{ml}$; Sigma-Aldrich, catalog \#A5316, RRID: AB_476743; TUJ 1, $0.1 \mu \mathrm{g} / \mathrm{ml}$, BioLegend, catalog \#802001, RRID:AB_2564645; GST, $0.2 \mu \mathrm{g} / \mathrm{ml}$; Abcam, catalog \#ab9085, RRID:AB_306993; SBP, $0.04 \mu \mathrm{g} / \mathrm{ml}$; Santa Cruz Biotechnology, catalog \#sc-101595, RRID:AB_1128239; RhoA, 0.4 $\mu \mathrm{g} / \mathrm{ml}$; Santa Cruz Biotechnology, catalog \#sc-418, RRID:AB_628218). The primary antibody for mouse LOTUS was developed by ITM and applied at a concentration of $0.425 \mu \mathrm{g} / \mathrm{ml}$. After the membrane was washed with TBST three times, the membrane was incubated with HRP-conjugated secondary antibody (anti-mouse IgG, 1:5000, GE Healthcare, catalog \#NA931, RRID:AB_772210, GE Healthcare; anti-rabbit IgG, 1:5000, GE Healthcare, catalog \#NA934, RRID:AB_772206; anti-rat IgG, $0.16 \mu \mathrm{g} / \mathrm{ml}$; Jackson ImmunoResearch Laboratories, catalog \#112-035-003 RRID:AB_2338128; anti-goat IgG, $0.08 \mu \mathrm{g} / \mathrm{ml}$; Jackson ImmunoResearch Laboratories, catalog \#705-035-147, RRID:AB_2313587) for $1 \mathrm{~h}$ at RT with constant agitation. The membrane was incubated with Immobilon Western Chemiluminescent HRP substrate (Merck Millipore) or Western blot Ultra Sensitive HRP Substrate (Takara) at RT and the signals were detected with ImageQuant LAS 4000 Mini (GE Healthcare) using ImageQuant (GE Healthcare, RRID:SCR_014246). The brightness and contrast of the images were adjusted with ImageJ software (RRID: SCR_003070).

Growth cone collapse assay. The assay was performed as described previously (Sato et al., 2011; Kurihara et al., 2014). For chick DRG neurons, explants of DRG obtained from E13.5 chick embryos of either sex were plated on $35 \mathrm{~mm}$ glass-base dishes (Asahi Glass, catalog \#3911-035), which were sequentially coated with PLL $(100 \mu \mathrm{g} / \mathrm{ml}$; Wako $)$ and laminin (10 $\mu \mathrm{g} / \mathrm{ml}$; Invitrogen, catalog \#23017-015) and cultured for $24 \mathrm{~h}$ in Ham's F-12 containing 10\% FBS (Biological Industries) and NGF (10 $\mathrm{ng} / \mathrm{ml}$; Sigma-Aldrich). For mouse olfactory bulb (OB) neurons, fragments of the OB obtained from E13.5 lotus-KO mouse embryos of either sex were plated as explants on PLL-coated $35 \mathrm{~mm}$ glass-base dishes (Asahi Glass) and cultured for $48 \mathrm{~h}$ in neurobasal medium (Invitrogen) with 1\% Glutamax (Invitrogen) and 2\% B27 (Invitrogen). Explants were treated sequentially with SBP-Fc-LOTUS or SBP-Fc $(1 \mu \mathrm{M})$ for $30 \mathrm{~min}$ at $37^{\circ} \mathrm{C}$ with $5 \% \mathrm{CO}_{2}$ and then each MAI [Nogo66-Fc (200 nM, catalog \#3728-NG), MAG-Fc (20 nM, catalog \#538-MG) and OMgp-10His (50 nM, catalog \#1674-MG) purchased from R\&D Systems] or PBS was added in the culture medium for $30 \mathrm{~min}$ at $37^{\circ} \mathrm{C}$ with $5 \% \mathrm{CO}_{2}$. Explants were fixed with $4 \%$ PFA in PBS for 10 min without washing step at $37^{\circ} \mathrm{C}$ and then fixed again for $10 \mathrm{~min}$ at RT. The cells were washed with TBST, permeabilized with PBS containing $0.1 \%$ Triton X-100 for $10 \mathrm{~min}$ at RT, and stained with Alexa Fluor 488-conjugated phalloidin $(0.8 \mathrm{U} / \mathrm{ml}$; Invitrogen) for $1 \mathrm{~h}$ at RT in the dark. Photographs were taken with Keyence BZ-8100. The growth cone collapse rate was measured as described previously (Kapfhammer et al., 2007; Sato et al., 2011; Kurihara et al., 2014). The growth cone on longer axons in each explant was observed. A growth cone with three or more filopodia was categorized as "not collapsed," and a growth cone with two or fewer filopodia was categorized as "collapsed." Collapse rates are shown as the percentages of collapsed growth cones of all of the growth cones observed.

Neurite outgrowth assay. Multiple four-well dishes (Thermo Fisher Scientific, catalog \#176740) were coated sequentially with PLL (100 $\mu \mathrm{g} /$ $\mathrm{ml}$; Wako) and each MAI [Nogo66-Fc (200 nм; R\&D Systems, catalog \#3728-NG), SBP-AP-MAG (30 nM), OMgp-10His (50 nM, catalog $\# 1674-\mathrm{MG})]$ or PBS for $1 \mathrm{~h}$ at $37^{\circ} \mathrm{C}$ with $5 \% \mathrm{CO}_{2}$. DRG neurons obtained from E13.5 chick embryos of either sex were dissociated with $0.25 \%$ trypsin (Invitrogen, catalog \#15090-046) and cultured at a density of $6 \times$ $10^{3}$ cells/well in Ham's F-12 containing 10\% FBS (Biological Industries) and NGF (10 ng/ml; Sigma-Aldrich). After ensuring that almost all cells were attached to the bottom of the wells, the cells were treated with SBP-Fc-LOTUS or SBP-Fc $(1 \mu \mathrm{M})$ for $24 \mathrm{~h}$ at $37^{\circ} \mathrm{C}$ with $5 \% \mathrm{CO}_{2}$. The treated cells were fixed with $4 \%$ PFA in the culture medium for $10 \mathrm{~min}$ at $37^{\circ} \mathrm{C}$ and then fixed again for $10 \mathrm{~min}$ at RT. The fixed cells were washed with TBST, permeabilized with PBS containing $0.1 \%$ Triton X-100 (PBS-
Tx) for 10 min at RT, blocked with PBS-Tx containing $1 \%$ bovine serum albumin for $1 \mathrm{~h}$ at RT, and immunostained with an anti- $\alpha$ tubulin antibody $(1 \mu \mathrm{g} / \mathrm{ml}$; Santa Cruz Biotechnology, catalog \#sc-32293, RRID: AB_628412) for $1 \mathrm{~h}$ at RT and with a secondary antibody conjugated with Alexa Fluor $488(1.5 \mu \mathrm{g} / \mathrm{ml}$; Jackson ImmunoResearch Laboratories, catalog \#115-545-003, RRID:AB_2341099) for $1 \mathrm{~h}$ at RT in the dark. Only clearly discernible neurons were observed and photographs were taken with a BZ-8100 microscope (Keyence). The distance from the initial neurite segment to the tip of the longest neurite in each neuron was measured with ImageJ software. Neurons in which the longest neurite was shorter than the diameter of the cell body were excluded.

Optic nerve crush injury. Optic nerve injury was performed as described previously (Smith et al., 2009). Briefly, after postnatal day 21, WT mice of either sex were anesthetized with $2 \%$ tribromoethanol $(250 \mathrm{mg} /$ $\mathrm{kg}$ ) and their left optic nerve was exposed intraorbitally and crushed at $\sim 1 \mathrm{~mm}$ distal from the eyeball for $7 \mathrm{~s}$ with sharp forceps with the lens capsule intact. For treatment, $2 \mu \mathrm{l}$ of SBP-Fc-LOTUS or SBP-Fc $(10 \mu \mathrm{M})$ was injected twice with a glass pipette intravitreously immediately after the crush injury and on postoperative day (POD) 7. Two microliters of Alexa Fluor 555-conjugated Cholera toxin subunit B (CTB; Thermo Fisher Scientific, catalog \#C-22843) was injected intravitreously as a neuronal tracer on POD 12 and the mouse was perfused transcardially with 2\% PFA in PBS ( $40 \mathrm{ml} /$ body) for $10 \mathrm{~min}$ (see Fig. $7 A$ ) on POD 14. The injured optic nerve with the eyecup was enucleated and fixed with $4 \%$ PFA in PBS overnight at $4^{\circ} \mathrm{C}$. The tissue was dehydrated with $10-30 \%$ sucrose overnight at $4^{\circ} \mathrm{C}$, embedded in optimal cutting temperature compound (Sakura Finetek) and snap frozen with liquid nitrogen. Serial longitudinal sections of $16 \mu \mathrm{m}$ thickness were prepared with a cryostat (Leica Biosystems, catalog \#CM1860) and collected on MAS-coated glass slides (Matsunami Glass). Photographs were taken with a BZ-8100 microscope (Keyence) and analyzed using a BZ Analyzer (Keyence). The number of CTB-labeled regenerated axons at $0.25,0.5$, and 0.75 distal to the end of the injury site was counted. The cross-sectional width of the nerve was measured at each point where regenerated axons were measured and the value was used to calculate the number of axons per millimeter of nerve width. This number at each point was calculated from four different sections and averaged $\left(N_{\mathrm{av}}\right)$. The total number of axons in the optic nerve $(\Sigma)$ with a radius $(r)$ was estimated by summing the number in all four sections with a thickness $(t, 16 \mu \mathrm{m})$, using the following formula:

$$
\Sigma=\pi r^{2} \times N_{a v} / t
$$

For detection of s-LOTUS in the optic nerve, the crushed optic nerve around the injury site was enucleated on POD 0 or POD 8 and homogenized with the same lysis buffer as that used in the pull-down assay and the samples for Western blotting. Immunohistochemistry was also performed to confirm the presence of s-LOTUS in the crushed optic nerve. After intravitreous CTB injection on POD 6 and SBP-Fc-LOTUS on POD 0 and POD 7 in the optic nerve crush injury model described above, sections of an optic nerve obtained on POD 8 were treated with Alexa Fluor 488-conjugated anti-human IgG antibody (1:500; Jackson ImmunoResearch Laboratories, catalog \#709-545-149, RRID:AB_2340566) for $1 \mathrm{~h}$ at RT. Photographs were taken with a TCS SP8 camera (Leica).

Statistical analysis. All tests were performed in more than three independent experiments and the data are presented as the mean \pm SEM. Statistically significant differences were assessed by Student's $t$ test (for the pull-down assay), one-way ANOVA followed by Dunnett's multiplecomparisons tests (for the growth cone collapse assay in mouse OB neurons and the binding assay of SBP-Fc-LOTUS to p75 ${ }^{\mathrm{NTR}}, \mathrm{NgR} 1$, and p75 NTR/NgR1), two-way ANOVA followed by Tukey's multiple-comparisons test (for dose-dependent neurite outgrowth assay and the optic nerve crush injury), or one-way ANOVA followed by Tukey-Kramer's multiple-comparisons tests (for other experiments).

\section{Results \\ LOTUS interacts with $\mathrm{p} 75^{\mathrm{NTR}}$}

We defined s-LOTUS as a soluble protein that contains a signal peptide, four phenylalanyl-glycyl and glycyl-alanyl-prolyl 
A
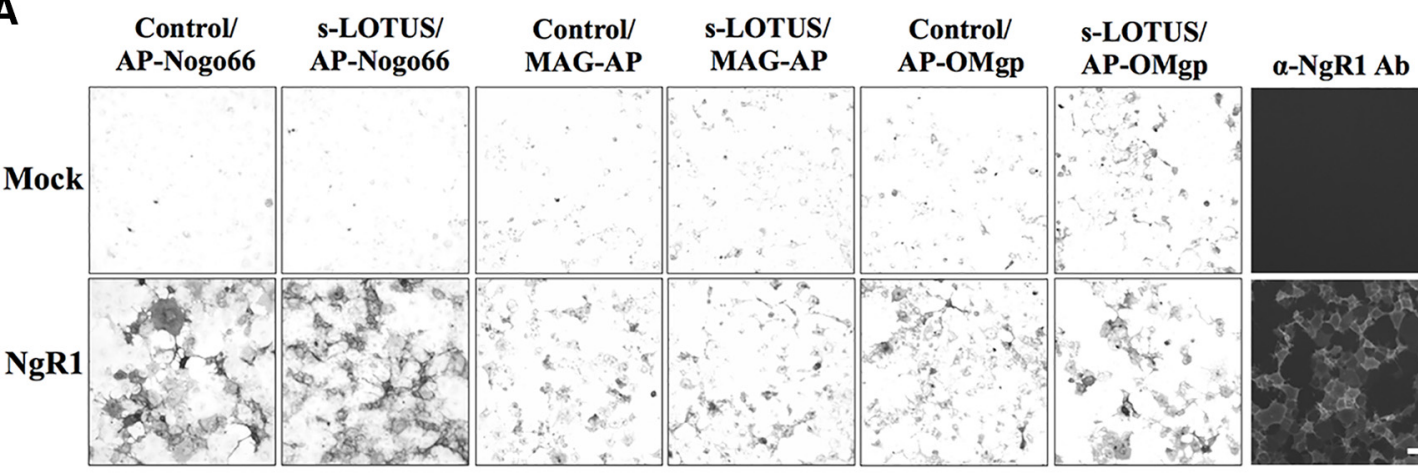

B

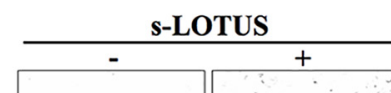

s-LOTUS a-p $-\mathbf{p} 5^{\mathrm{NTR}} \mathbf{A b}$
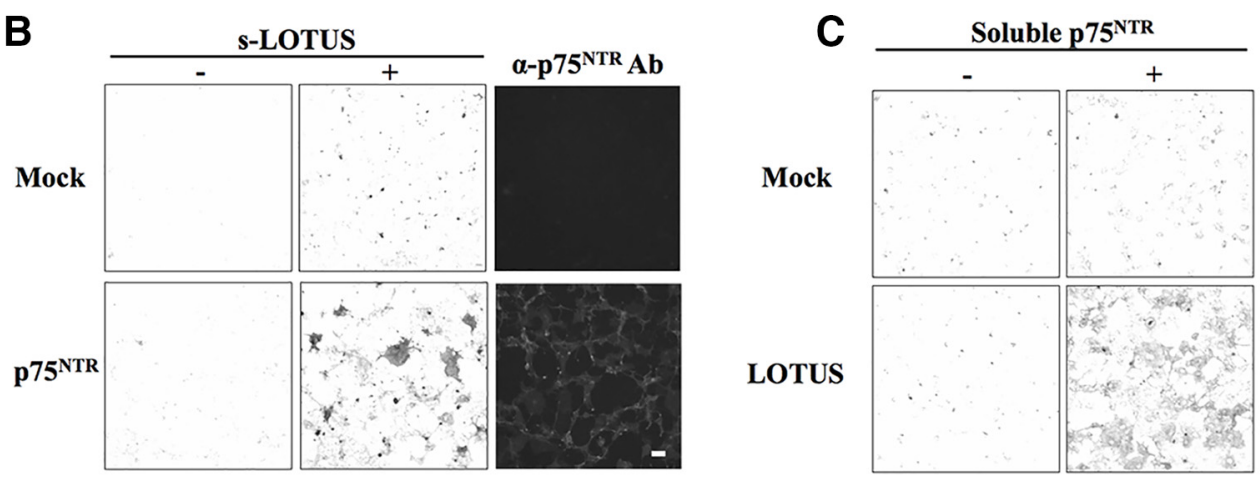

$\alpha$-LOTUS Ab

D

$\frac{\text { Lysate }}{\text { LOTUS/ }} \frac{\text { Pull-down }\left(\mathbf{p 7 5}^{\mathrm{NTR}}\right)}{\text { LOTUS/ }}$
Mock LOTUS p75

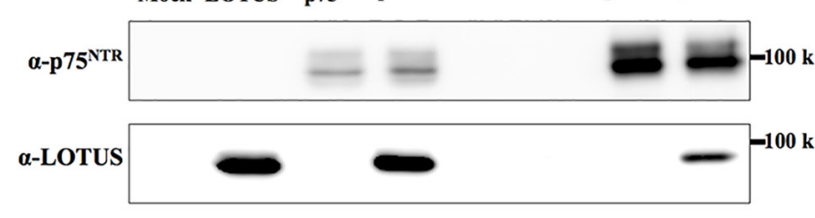

E
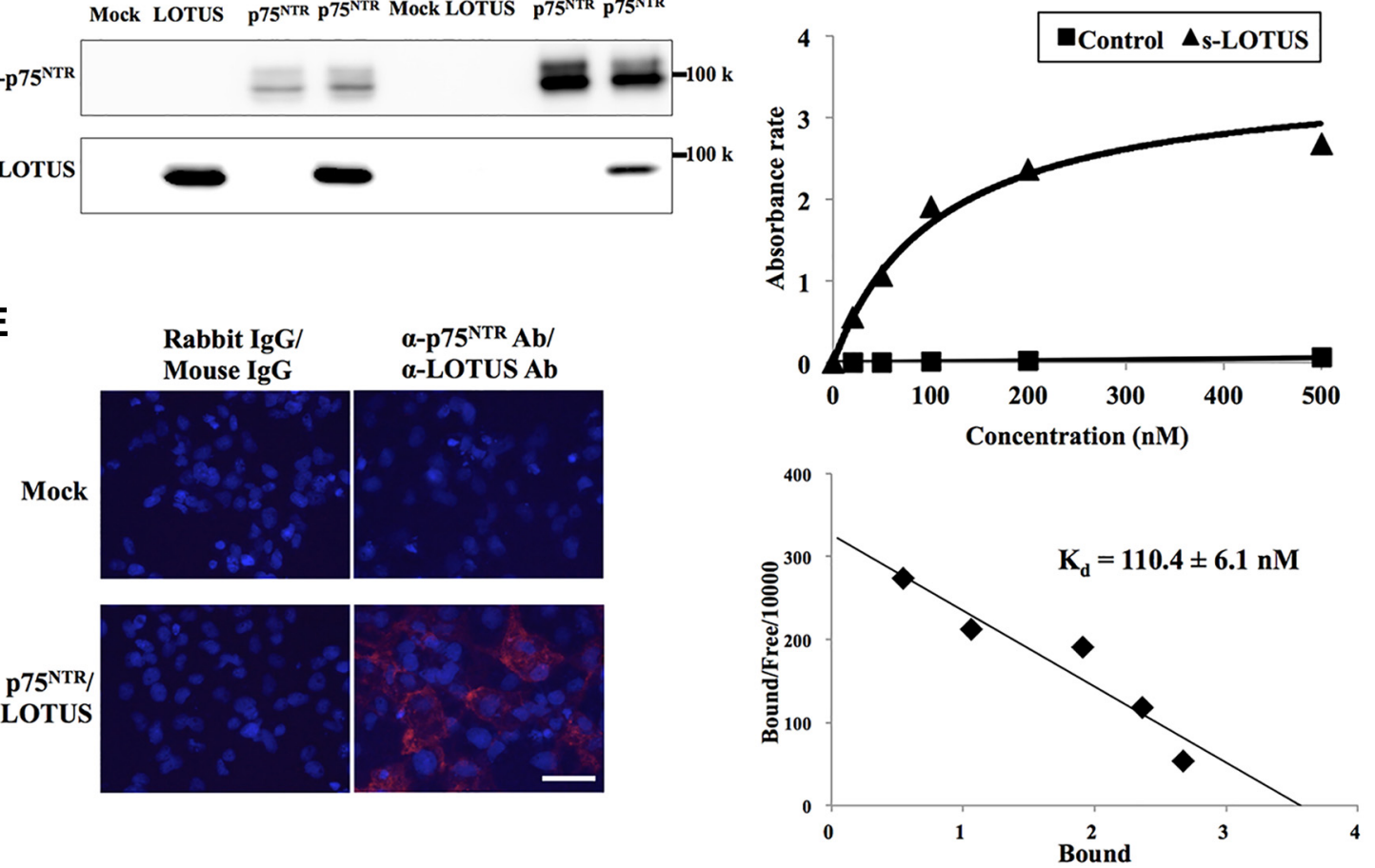

Figure 1. LOTUS binds to $\mathrm{p}^{\mathrm{NTR}}{ }^{\mathrm{NT}}$. A, Binding assay in NgR1-overexpressing Cos-7 cells sequentially treated with s-LOTUS and MAls. After SBP-Fc-LOTUS (0.1-1 $\left.\mu \mathrm{M}\right)$ or SBP-Fc (control) was applied to NgR1-overexpressing Cos-7 cells and followed by 6His-AP-tagged MAls (6His-AP-Nogo66, 3 nm; MAG-AP-6His, 20 nм; 6His-AP-0Mgp, 50 nM), each MAl was detected with AP substrate. Scale bar, $100 \mu \mathrm{m}$. B, Binding assay in p75 ${ }^{\text {NTR }}$-overexpressing Cos-7 cells treated with s-LOTUS. SBP-Fc-LOTUS or its vehicle was applied and detected by immunostaining with an anti-SBP-tag antibody. Scale bar, $100 \mu \mathrm{m}$. C, Binding assay in LOTUS-overexpressing Cos-7 cells treated with soluble p $75^{\mathrm{NTR}}$. p75 ${ }^{\mathrm{NTR}}$-Fc-SBP or its vehicle was applied and detected in the same way as in $\boldsymbol{B}$. Scale bar, $100 \mu \mathrm{m}$. D. Pull-down assay in p75 NTR and LOTUS co-overexpressing Cos-7 cells. GST-p 75 ${ }^{\text {NTR }}$ and SBP-FLAG-LOTUS were co-overexpressed and the cell lysate was incubated with glutathione Sepharose beads. SBP-FLAG-LOTUS and GST-p $75^{\text {NTR }}$ were detected by Western blotting using an anti-SBP-tag antibody and an anti-GST antibody, respectively. $\boldsymbol{E}$, Representative images of PLA signals (red) after treatment with primary antibodies before fixation in Cos-7 cells overexpressing both GST-p75 and SBP-FLAG-LOTUS. Red signals represent the close colocalization and interaction between LOTUS and p75 NTR on the cell membrane surface. Cells were costained with DAPI (blue). Scale bar, $50 \mu \mathrm{m}$. F, Binding affinity of LOTUS for p75 ${ }^{\text {NTR }}$ examined by ELISA using SBP-Fc-p75 NTR and LOTUS-Fc-6His or Fc-6His (control). Scatchard plot shows $K_{\mathrm{d}}=110.4 \pm 6.1 \mathrm{~nm}$. The data were obtained from four independent experiments. 
A
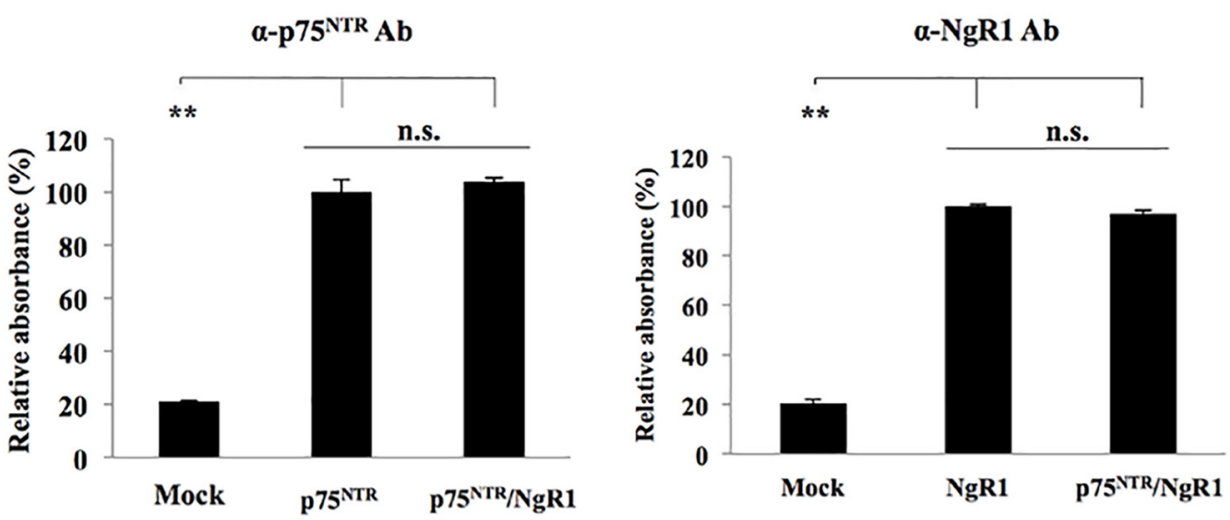

B
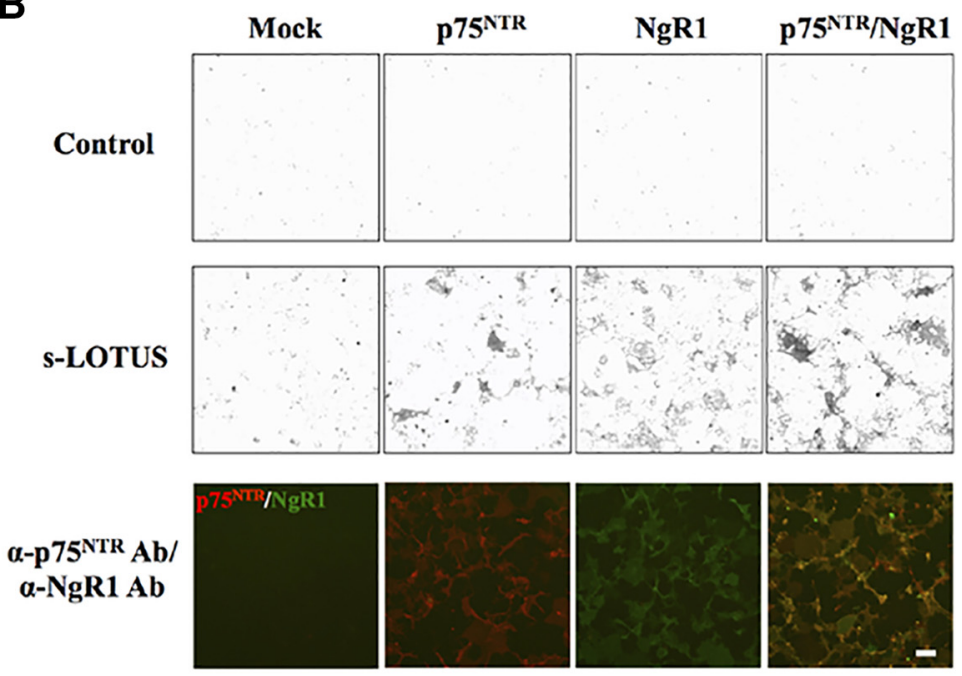

C
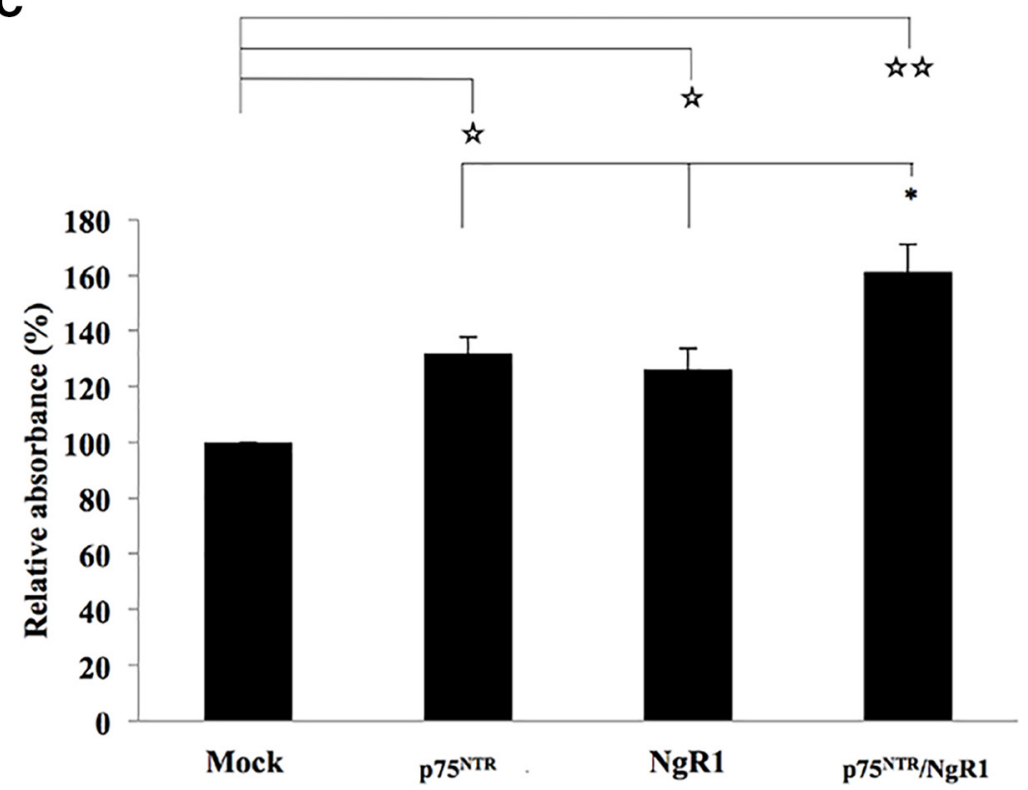

Figure 2. s-LOTUS binds to $\mathrm{p} 75^{\mathrm{NTR}}$ independently of binding to NgR1. A, Quantification of expression levels of $\mathrm{p} 75^{\mathrm{NTR}}$ and NgR1 on the cell membrane surface in Cos-7 cells overexpressing p $75^{\mathrm{NTR}}$ alone, $\mathrm{NgR} 1$ alone, or both $\mathrm{p} 75^{\mathrm{NTR}}$ and NgR1 proteins. The data are presented as the mean \pm SEM obtained in duplicate from three independent experiments. ${ }^{* *} p<0.01$ versus control: one-way ANOVA (Tukey-Kramer). B, Representative images of the binding assay of SBP-Fc-LOTUS in Cos-7 cells overexpressing p $75^{\mathrm{NTR}}$, NgR1, or both p $75^{\mathrm{NTR}}$ and NgR1. Cell surface expression of each protein was confirmed by immunostaining with anti-p75 NTR antibody (red) and anti-NgR1 antibody (green) before fixation. Scale bar, $100 \mu \mathrm{m}$. C, Quantitative analysis of s-LOTUS binding to $\mathrm{p} 755^{\mathrm{NTR}}$ and/or $\mathrm{NgR1}$ shown in $\boldsymbol{B}$. The binding of SBP-Fc-LOTUS to each protein was detected by immunostaining with an anti-SBP-tag antibody, AP-conjugated avidin-biotin complex, and pNPP. The absorbance at $405 \mathrm{~nm}$ was measured and normalized to the binding level in cells transfected with mock vector. The data are presented as the mean \pm SEM obtained in duplicate from five independent

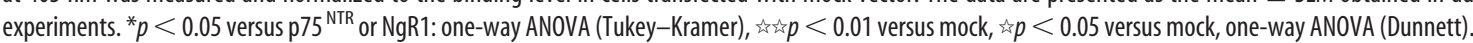


A
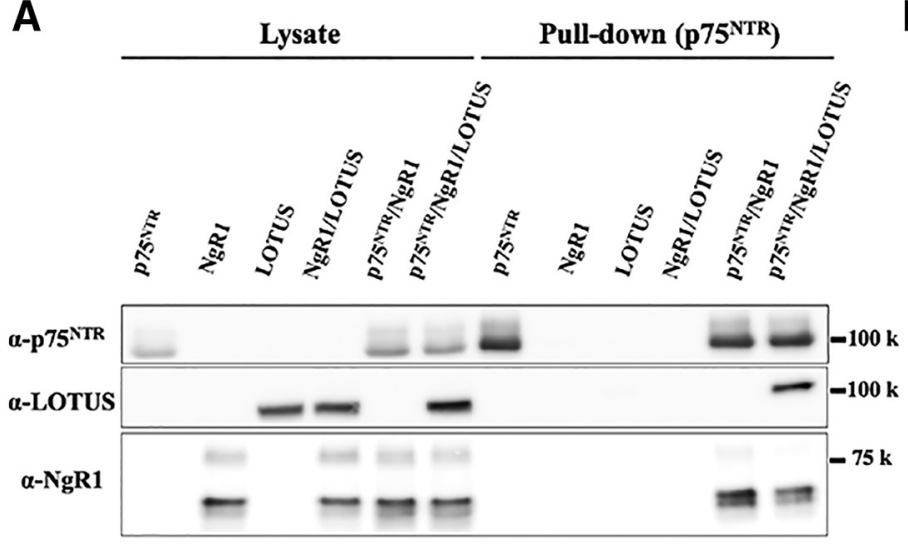

C
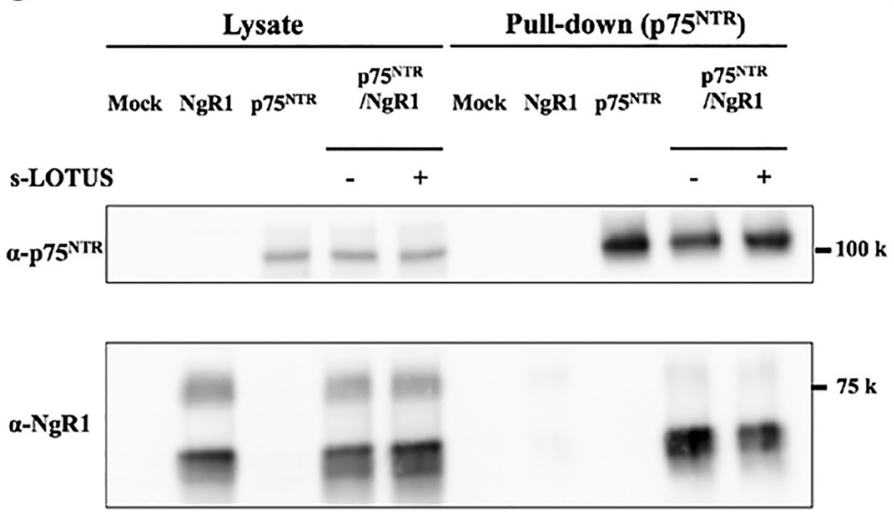

E

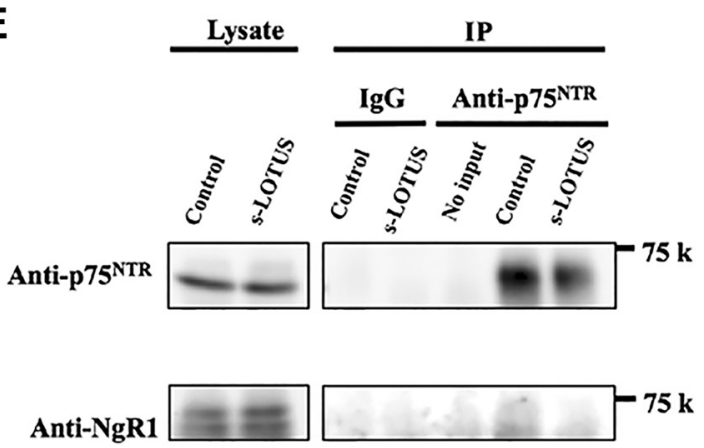

G

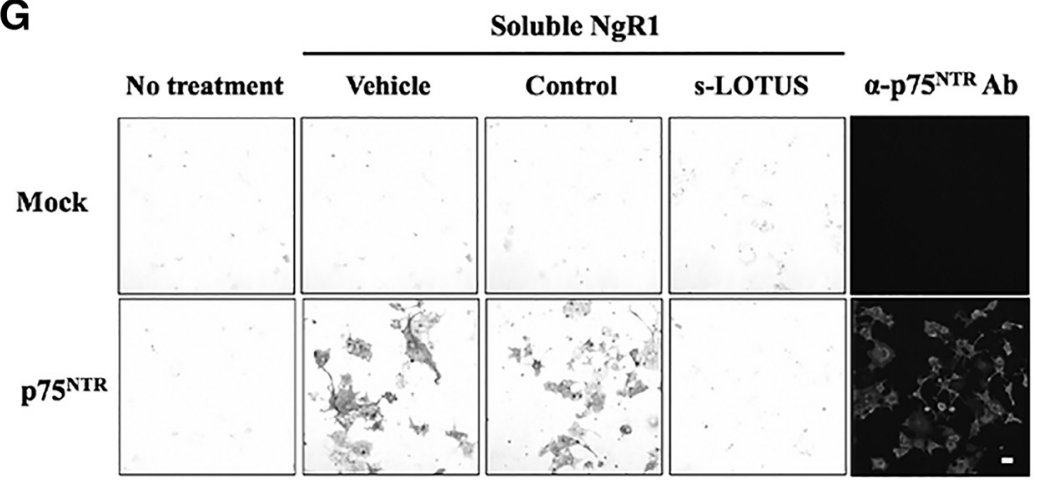

B

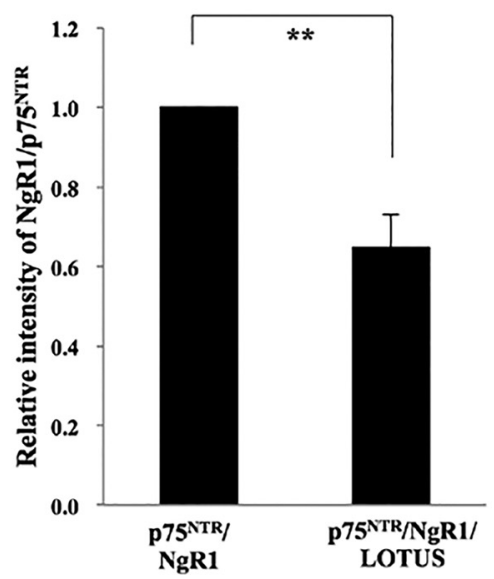

D

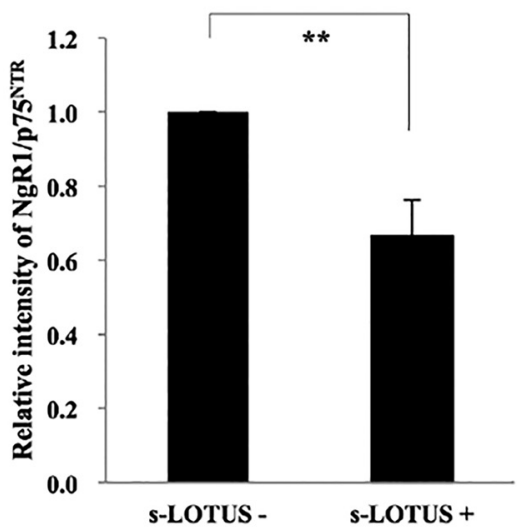

$\mathbf{F}$

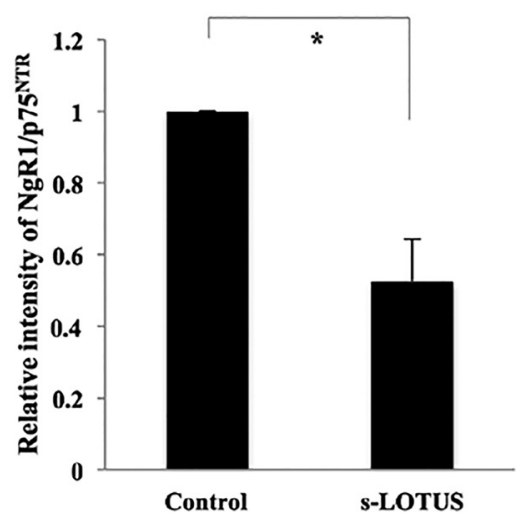

Figure 3. LOTUS inhibits the interaction between p75NTR and NgR1. A, Pull-down assay in HEK293T cells overexpressing p75NTR, NgR1, and LOTUS. HEK293T cells overexpressing GST-p75NTR, NgR1, and SBP-FLAG-LOTUS were incubated with glutathione Sepharose beads. Each protein was detected by Western blotting using an anti-GST antibody, an anti-NgR1 antibody, or an anti-SBP-tag antibody. $\boldsymbol{B}$, Quantitative analysis of relative intensity of NgR1 in the pull-down product in $\boldsymbol{A}$. The relative intensity of NgR1 to p75NTR in HEK293T cells overexpressing GST-p75NTR, $\mathrm{NgR1}$, and SBP-FLAG-LOTUS was normalized to the intensity level of that in HEK293T cells overexpressing GST-p75NTR and NgR1. Values are expressed as the mean \pm SEM $(n=5)$. ** $p<0.01$ versus without LOTUS expression, Student's $t$ test. C, Pull-down assay in HEK293T cells overexpressing both p75NTR and NgR1 treated with or without s-LOTUS. HEK293T cells overexpressing both GST-p75NTR and NgR1 were treated with SBP-Fc-LOTUS $(1 \mu \mathrm{m})$ or its vehicle in both culture medium and prepared cell lysate and incubated with glutathione (Figure legend continues.) 
(FG-GAP) domains, a UnbV/ASPIC (UA) domain, and an EGFlike calcium binding (EC) domain of mouse LOTUS (Steck et al., 2007). We investigated whether s-LOTUS blocks ligand binding to $\mathrm{NgR} 1$ overexpressed in Cos-7 cells. Surprisingly, in contrast to the membrane-bound form of LOTUS, s-LOTUS did not block the binding of MAIs to NgR1 (Fig. 1A). Further investigation revealed that s-LOTUS bound to $\mathrm{p} 75^{\mathrm{NTR}}$, a coreceptor of NgR1, overexpressed in Cos-7 cells (Fig. $1 B$ ) and that the soluble ectodomain of $\mathrm{p} 75^{\mathrm{NTR}}$ bound to LOTUS overexpressed in Cos-7 cells (Fig. 1C). To confirm the interaction of LOTUS with p $75^{\text {NTR }}$, we performed a pull-down assay in Cos-7 cells cooverexpressing SBP-FLAG-LOTUS and GST-p75 NTR. Specific binding of LOTUS with p $75^{\text {NTR }}$ was observed in the pull-down product (Fig. 1D). For further confirmation, we performed PLA in Cos-7 cells cooverexpressing SBP-FLAG-LOTUS and GST-p75 ${ }^{\mathrm{NTR}}$ to show close colocalization and interaction between LOTUS and p $75^{\mathrm{NTR}}$ on the cell membrane surface, which revealed that LOTUS and $p 75^{\mathrm{NTR}}$ interacted with each other on the cell membrane surface (Fig. 1E). To examine the binding of LOTUS with p $75^{\mathrm{NTR}}$, we also performed ELISA using LOTUS-Fc-6His and SBP-Fc-p $75^{\text {NTR }}$ and demonstrated that the $K_{\mathrm{d}}$ value was $110.4 \pm$ $6.1 \mathrm{~nm}$ (Fig. 1F).

We confirmed that LOTUS binds to $\mathrm{p} 75^{\mathrm{NTR}}$. We next investigated whether the binding activity of LOTUS to $\mathrm{p} 75^{\mathrm{NTR}}$ is influenced by binding to $\mathrm{NgR} 1$. To address this issue, we performed a binding assay using SBP-Fc-LOTUS in Cos-7 cells overexpressing $\mathrm{p} 75^{\mathrm{NTR}}$ alone, NgR1 alone, or both $\mathrm{p} 75^{\mathrm{NTR}}$ and NgR1 proteins. Before the experiment, we confirmed that the $\mathrm{p} 75^{\mathrm{NTR}}$ or NgR1 expression levels on the cell surface in cells overexpressing a single protein were equivalent to that in cells overexpressing both proteins and that $\mathrm{p} 75^{\mathrm{NTR}}$ and $\mathrm{NgR} 1$ overexpression largely merged on the cell membrane surface (Fig. 2A,B). The binding assay revealed that $s$-LOTUS bound to each receptor additively (Fig. $2 C$ ), suggesting that the binding of s-LOTUS with $p 75^{\text {NTR }}$ occurs independently of that with NgR1.

\section{LOTUS inhibits the binding of NgR1 to $\mathrm{p} 75^{\mathrm{NTR}}$}

We next investigated whether the interaction of LOTUS with p $75^{\mathrm{NTR}}$ or NgR1 affects the binding of NgR1 to p $75^{\mathrm{NTR}}$. The results of a pull-down assay in HEK293T cells overexpressing GST-p75 ${ }^{\text {NTR }}$, NgR1, and SBP-FLAG-LOTUS revealed that coexpression of LOTUS inhibited the interaction between NgR1 and p $75^{\text {NTR }}$ significantly (Fig. $3 A, B$ ). To further investigate whether s-LOTUS also inhibits the binding between NgR1 and $p 75^{\mathrm{NTR}}$, we performed a pull-down assay with SBP-Fc-LOTUS applied to both culture medium and prepared cell lysate during incubation

\footnotetext{
$\leftarrow$

(Figure legend continued.) Sepharose beads. Each protein was detected by Western blotting using an anti-GST antibody or an anti-NgR1 antibody. D, Quantitative analysis of the relative intensity of $\mathrm{NgR} 1$ in the pull-down product in C. The relative intensity of $\mathrm{NgR1}$ to $\mathrm{p75NTR}$ with SBP-Fc-LOTUS treatment was normalized to the intensity level of that without SBP-FC-LOTUS treatment. Values are expressed as the mean $\pm \operatorname{SEM}(n=4) .{ }^{* *} p<0.01$ versus without SBP-Fc-LOTUS treatment (s-LOTUS ${ }^{-}$), Student's $t$ test. $E$, Representative images of immunoprecipitation of $\mathrm{P7}$ lotus-KO mice-derived cerebellar granule neurons treated with SBP-FLAGtagged LOTUS or SBP-AP (1 $\mu \mathrm{M})$ and incubated with anti-p75NTR Ab and protein A Sepharose beads. $\boldsymbol{F}$, Quantitative analysis of the relative intensity of $\mathrm{NgR} 1$ in the immunoprecipitation product in $\boldsymbol{E}$. The relative intensity of NgR1 to p75NTR with SBP-FLAG-LOTUS treatment was normalized to the intensity level of that without SBP-AP (control) treatment. Values are expressed as the mean $\pm \operatorname{SEM}(n=3) .{ }^{*} p<0.05$ versus control, Student's ttest. G, Binding assay in p75NTR-overexpressing Cos-7 cells sequentially treated with s-LOTUS and soluble NgR1. LOTUS-Fc-6His (100 nM) or Fc-6His (control) was applied, followed by soluble NgR1-Fc-SBP (20 nM). NgR1-Fc-SBP was detected using anti-SBP-tag antibody. Scale bar, $100 \mu \mathrm{m}$.
}

using glutathione Sepharose beads in HEK293T cells that overexpressed both GST-p75 ${ }^{\mathrm{NTR}}$ and NgR1 proteins. We found that incubation with s-LOTUS $(1 \mu \mathrm{M})$ decreased NgR1 coprecipitation with p $75^{\mathrm{NTR}}$ significantly (Fig. 3C,D). In addition, we confirmed that treatment with s-LOTUS suppressed $\mathrm{p} 75^{\mathrm{NTR}}-\mathrm{NgR} 1$ interaction in primary cultured cerebellar granule neurons from P7 lotus-KO mice (Fig. $3 E, F$ ). To confirm these results, we investigated whether s-LOTUS inhibits the binding of the soluble form of NgR1 to p $75^{\mathrm{NTR}}$ overexpressed in Cos-7 cells. Cos-7 cells overexpressing $\mathrm{p} 75^{\mathrm{NTR}}$ were treated sequentially with LOTUS-Fc6 His and NgR1-Fc-SBP. Treatment with s-LOTUS inhibited the binding of soluble NgR1 to $\mathrm{p} 75^{\mathrm{NTR}}$ (Fig. $3 G$ ). These results suggest that s-LOTUS inhibits the interaction of NgR1 with $\mathrm{p} 75^{\mathrm{NTR}}$.

\section{s-LOTUS inhibits MAI-induced RhoA activation in cultured cortical neurons}

To determine whether s-LOTUS inhibits NgR1 signaling at the downstream signal level, we performed a pull-down assay in cultured cortical neurons from mouse E18.5 embryos, which are used to assay RhoA activation (van Erp et al., 2015), using the Rho-binding domain of Rhotekin, to which the GTP-bound active form of RhoA (GTP-RhoA) binds specifically. We confirmed the expression of NgR1 and $\mathrm{p} 75^{\mathrm{NTR}}$, but endogenous LOTUS was not detected by Western blotting (Fig. 4A). Cultured cortical neurons were sequentially treated with SBP-Fc-LOTUS $(1 \mu \mathrm{M})$ or SBP-Fc, and Nogo66-Fc (200 nM) or MAG-Fc $(25 \mu \mathrm{g} / \mathrm{ml})$. We confirmed that treatment with s-LOTUS alone did not influence the state of RhoA activation (data not shown). Treatment with s-LOTUS followed by incubation with Nogo66 or MAG significantly decreased the intensity of the GTP-RhoA band compared with treatment without s-LOTUS (Fig. $4 B-E$ ). These findings suggest that treatment with s-LOTUS inhibits the signal transduction of NgR1 induced by MAI.

\section{s-LOTUS suppresses MAI-induced growth cone collapse and neurite outgrowth inhibition in cultured DRG neurons}

To determine whether s-LOTUS functionally inhibits NgR1mediated signaling, we performed functional analyses of growth cone collapse and neurite outgrowth inhibition dominantly caused by NgR1-mediated signaling in chick E13.5 DRG neurons (Fournier et al., 2003). We performed the assay with $1 \mu \mathrm{M}$ SBP-Fc-LOTUS for functional analyses, according to the findings obtained from the molecular interaction assay and the RhoA pull-down assay shown in Figures 2 and 3. Treatment with s-LOTUS did not influence growth cone collapse compared with controls, but s-LOTUS decreased the growth cone collapse rate induced by MAIs to its control level (Fig. 5A,B). Furthermore, treatment with s-LOTUS did not affect neurite outgrowth activity compared with controls, but s-LOTUS suppressed neurite outgrowth inhibition induced by MAIs to its control level (Fig. 6A, $B$ ). We also investigated the dose dependency of s-LOTUS in the neurite outgrowth assay and found that treatment of s-LOTUS suppressed Nogo66-induced outgrowth inhibition in a dose-dependent manner (Fig. 6C). Accordingly, these findings suggest that s-LOTUS suppresses MAI-induced growth cone collapse and neurite outgrowth inhibition.

\section{s-LOTUS rescued MAI-induced growth cone collapse in OB neurons from lotus-KO mice}

We have reported previously that cultured $\mathrm{OB}$ neurons obtained from E13.5 WT mice express both LOTUS and NgR1 proteins and are insensitive to MAI-induced growth cone collapse. However, the growth cones of $\mathrm{OB}$ neurons from lotus-KO mice 


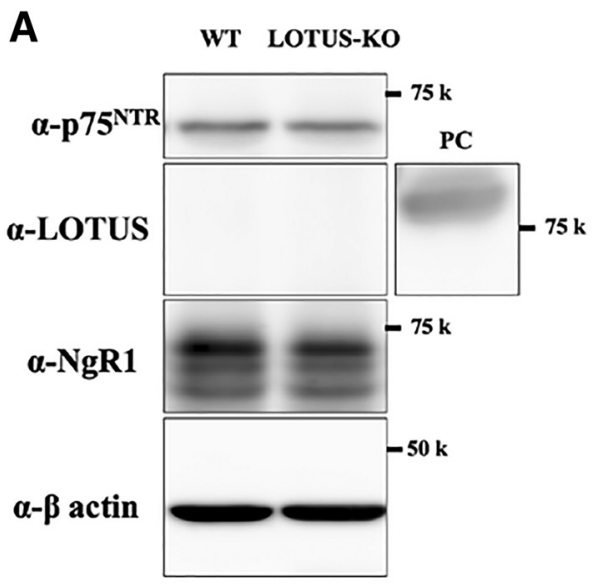

B

C

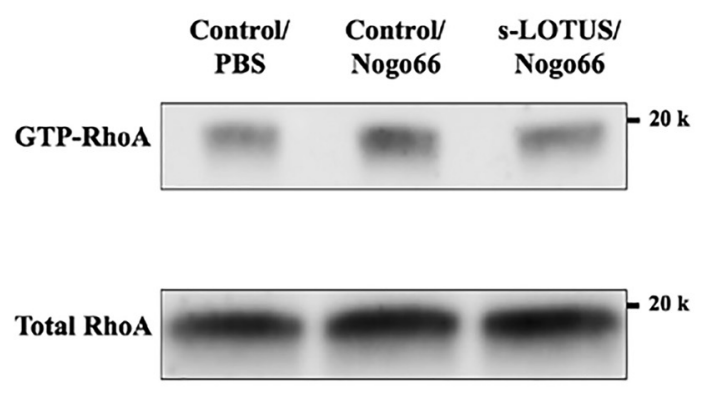

D

\section{$\mathbf{E}$}
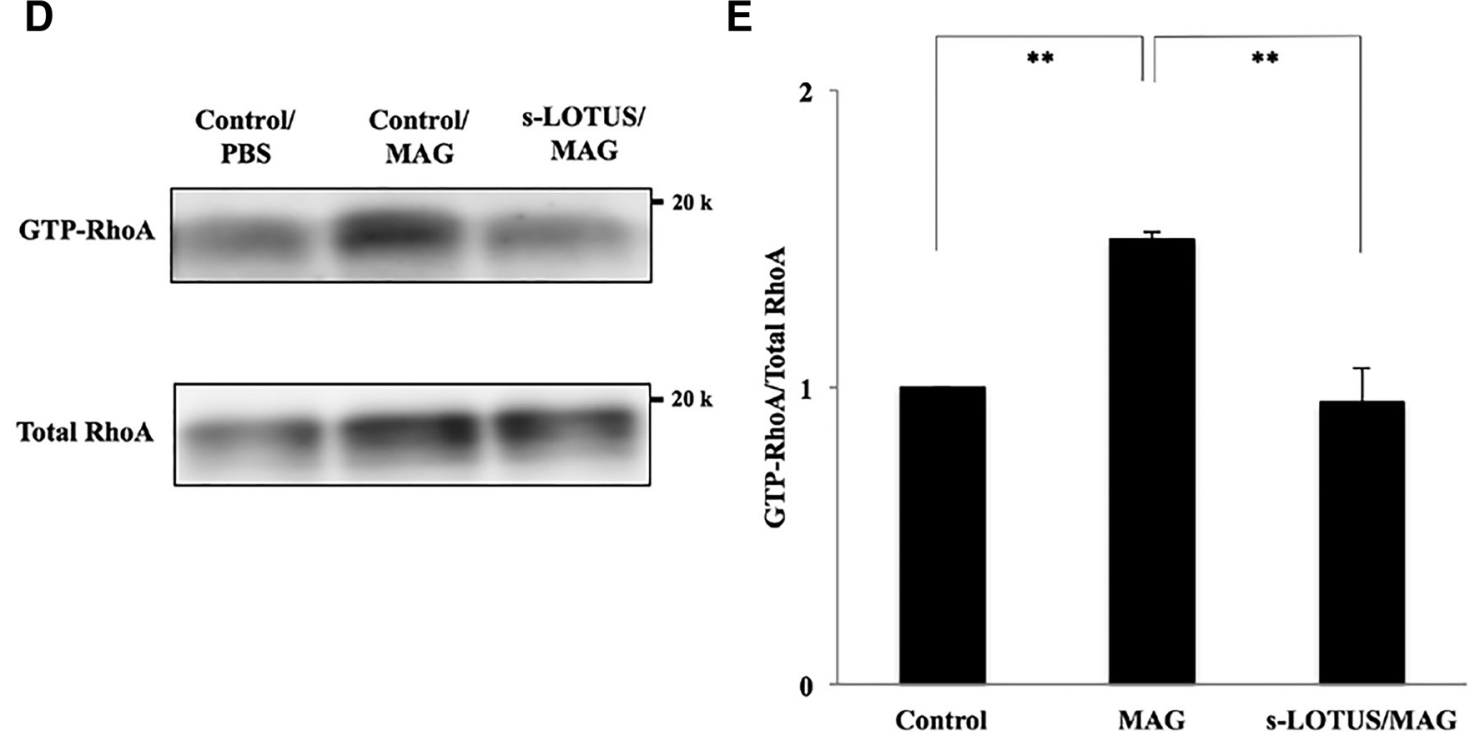

Figure 4. S-LOTUS inhibits RhoA activation induced by Nogo66 in cultured cortical neurons. $A$, Western blotting of cultured cortical neurons of E18.5 WT mice or lotus-K0 mice. $\beta$-actin was used as a loading control. Positive control (PC) of LOTUS was obtained from LOTUS-overexpressing Cos-7 cells. B, RhoA pull-down assay with Nogo66. Cultured E18.5 WT mouse cortical neurons were treated with SBP-Fc-LOTUS (1 $\mu \mathrm{M}$ ) or SBP-Fc (control) and Nogo66 (200 nM). Active GTP-bound RhoA was collected from prepared cell lysate using GST-tagged Rhotekin-Rho-GTP binding domain protein beads. Total RhoA and GTP-RhoA were detected by Western blotting using an anti-RhoA antibody. C, Quantitative analysis of relative intensity for GTP-bound RhoA in $\boldsymbol{B}$. The intensity levels of total RhoA and GTP-RhoA were quantified and the relative intensity of GTP-RhoA to total RhoA with SBP-Fc-LOTUS treatment was normalized to the intensity level of that without treatment (control). Values are expressed as the mean $\pm \operatorname{SEM}(n=4) .{ }^{* *} p<0.01$ versus Nogo66 treatment alone, ${ }^{*} p<0.05$ versus control: one-way ANOVA (Tukey-Kramer). $\boldsymbol{D}$, RhoA pull-down assay with MAG $(25 \mu \mathrm{g} / \mathrm{ml})$. E, Quantitative analysis of relative intensity for GTP-bound RhoA in D. Values are expressed as the mean \pm SEM $(n=4) .{ }^{* *} p<0.01$ versus MAG treatment alone: one-way ANOVA (Tukey-Kramer). 
A
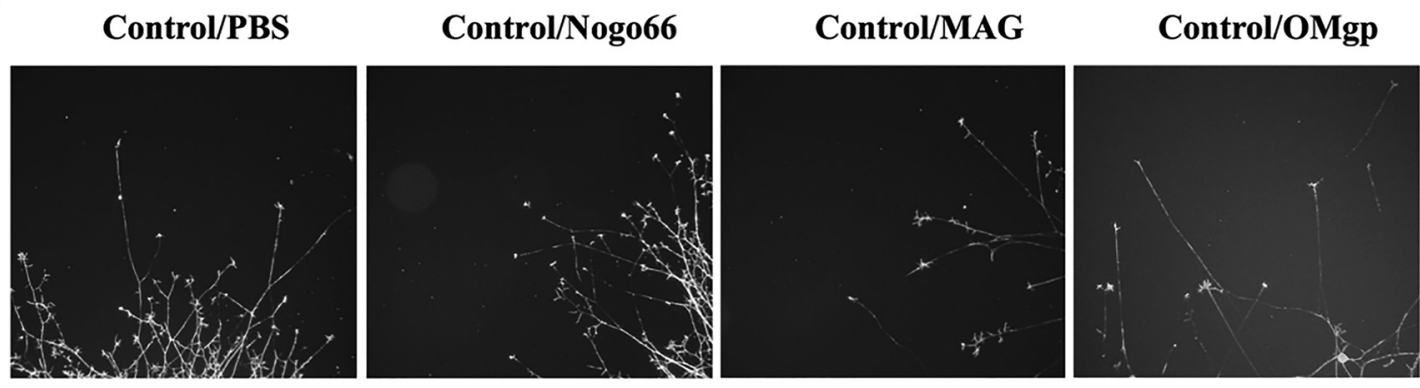

s-LOTUS/PBS

s-LOTUS/Nogo66

s-LOTUS/MAG

s-LOTUS/OMgp
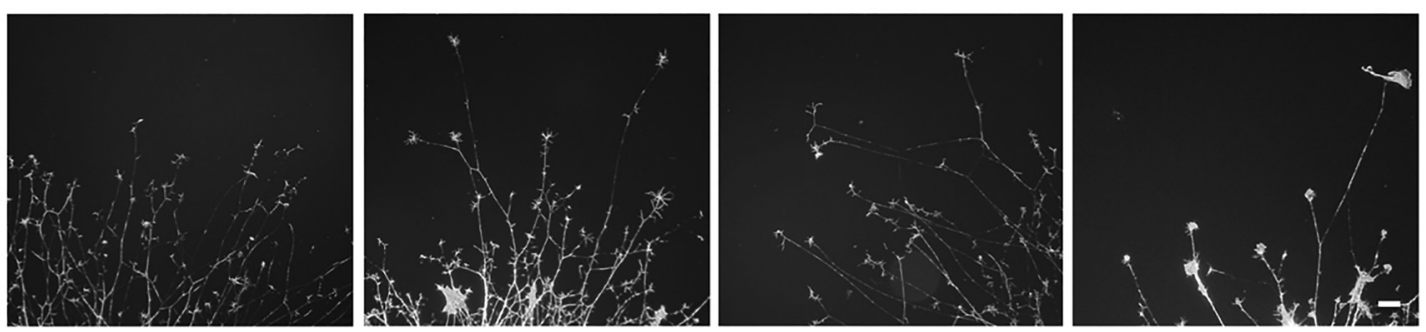

B
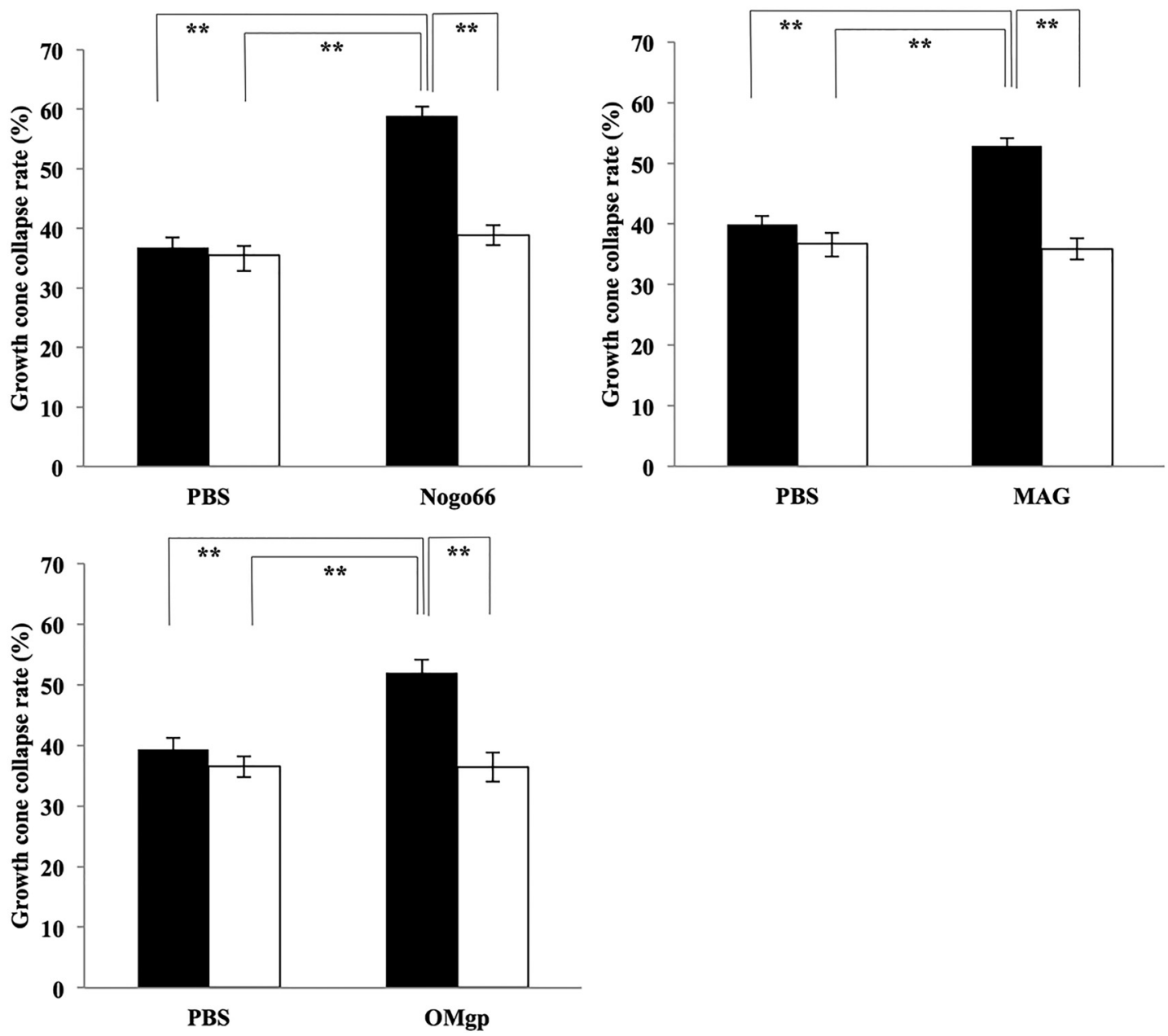

Figure 5. S-LOTUS inhibits MAl-induced growth cone collapse in chick DRG neurons. $\boldsymbol{A}$, Representative images of F-actin-stained growth cones of explanted E13.5 chick DRG neurons. Cultured chick DRG neurons were treated with SBP-Fc-LOTUS (1 $\mu$ M) or SBP-Fc (control) and each MAl (Nogo66-Fc: $200 \mathrm{~nm}$; MAG-Fc: $20 \mathrm{~nm}$; OMgp-10His: $50 \mathrm{~nm}$ ). Scale bar, $100 \mu \mathrm{m}$. B, Quantitative analysis of growth cone collapse in $A$. Filled bars indicate the collapse rates of growth cones without SBP-FC-LOTUS treatment, and open bars indicate with SBP-Fc-LOTUS treatment. Values are expressed as the mean $\pm \operatorname{SEM}(n=4) .{ }^{* *} p<0.01$, one-way ANOVA (Tukey-Kramer). 
A
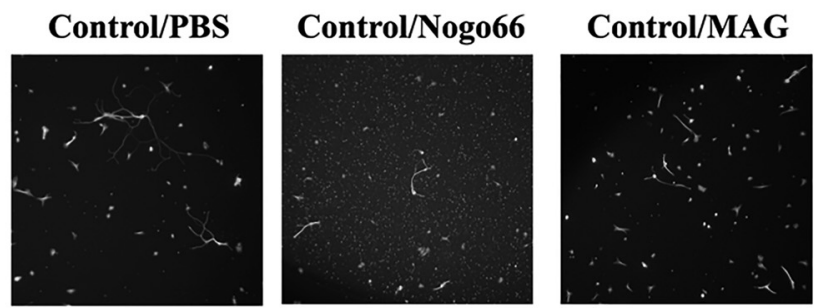

\section{Control/OMgp}
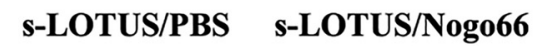

S-LOTUS/MAG
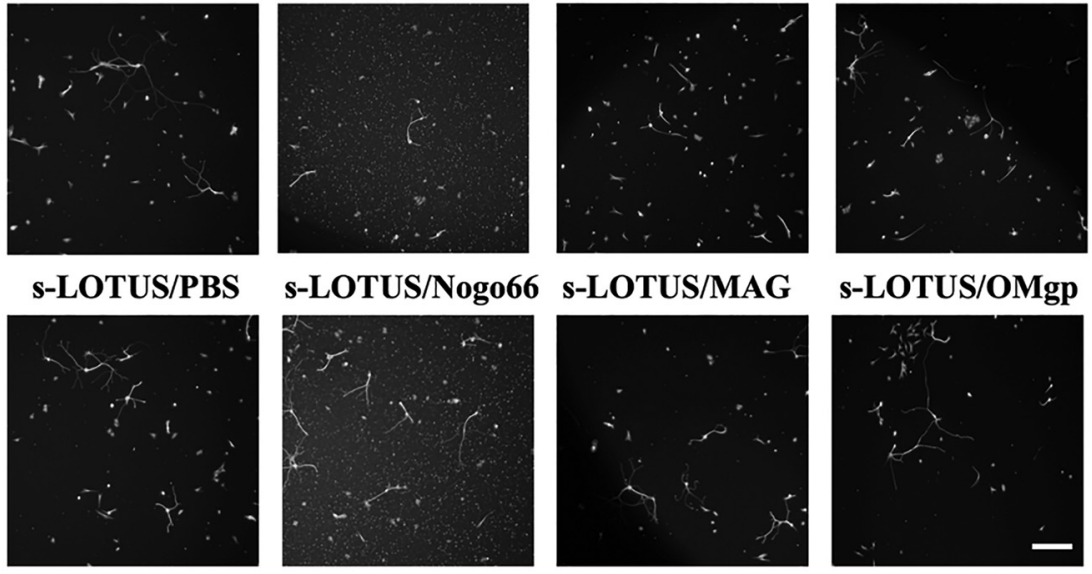

B
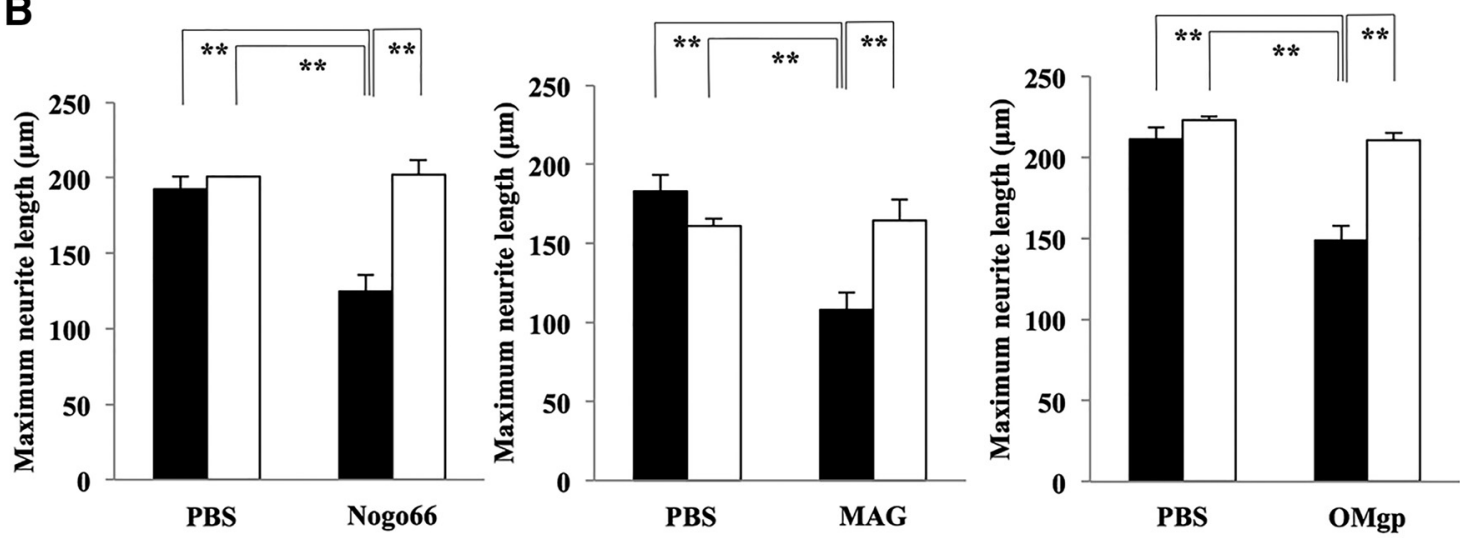

C

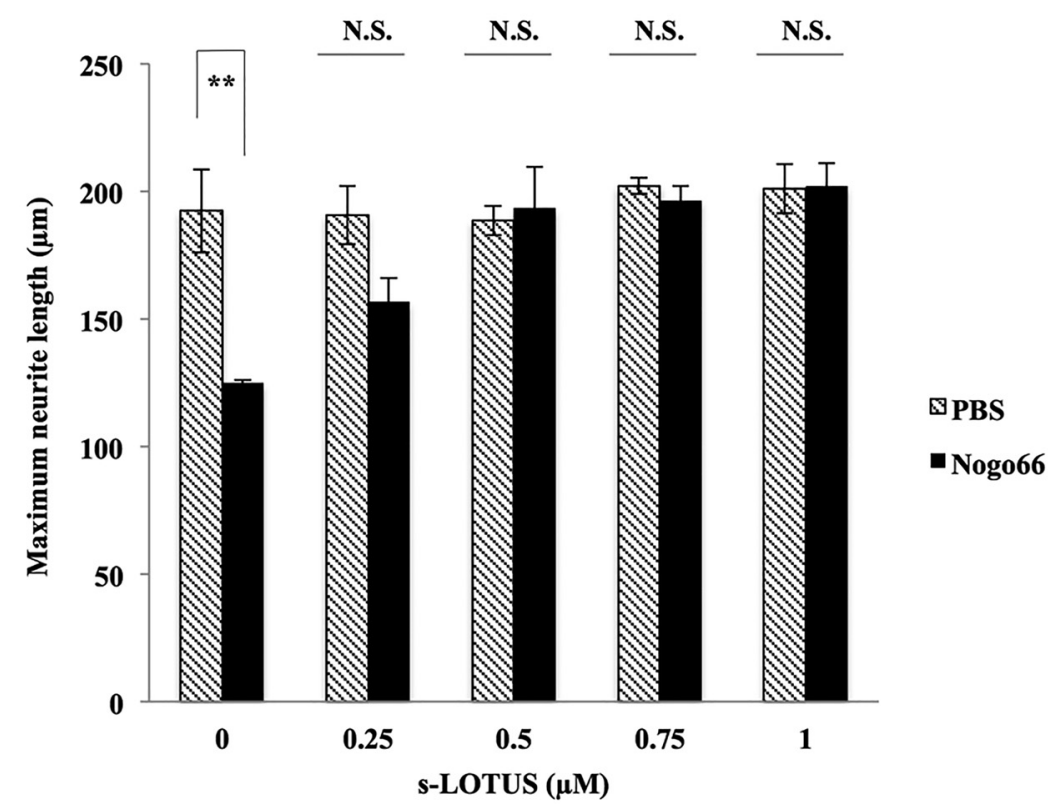

Figure 6. S-LOTUS suppresses MAI-induced neurite outgrowth inhibition in chick DRG neurons. $A$, Representative images of dissociated E13.5 chick DRG neurons stained by anti- $\alpha$-tubulin antibody. Chick DRG neurons were cultured with each MAI (Nogo66-Fc: $200 \mathrm{~nm}$; SBP-AP-MAG: $30 \mathrm{~nm}$; OMgp-10His: $50 \mathrm{~nm}$ ) and then treated with SBP-Fc-LOTUS (1 $\mu \mathrm{m}$ ) or SBP-Fc (control). Scale bar, $100 \mu \mathrm{m}$. B, Quantitative analysis of neurite length in $A$. Filled bars indicate the maximum neurite length without SBP-Fc-LOTUS treatment and open bars indicate the maximum neurite length with SBP-FC-LOTUS treatment. Values are expressed as the mean \pm SEM $(n=3-4) .{ }^{* *} p<0.01$ : one-way ANOVA (Tukey-Kramer). C, Quantitative analysis of dose-dependency of s-LOTUS in neurite length. Values are expressed as the mean \pm SEM $(n=3-4) .{ }^{* *} p<0.01$ versus PBS; two-way ANOVA followed by post hoc Tukey analysis. 
A

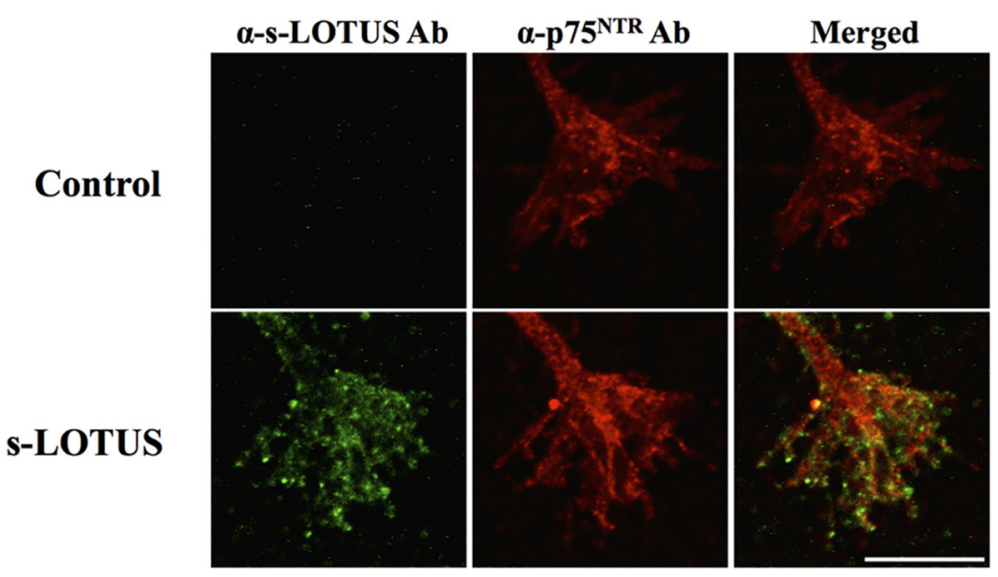

B

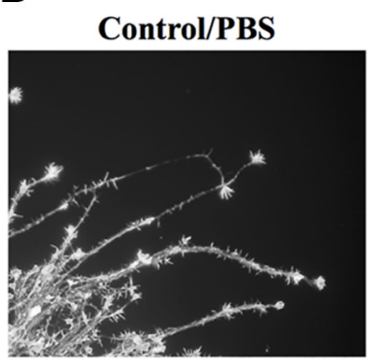

Control/Nogo66

Control/MAG
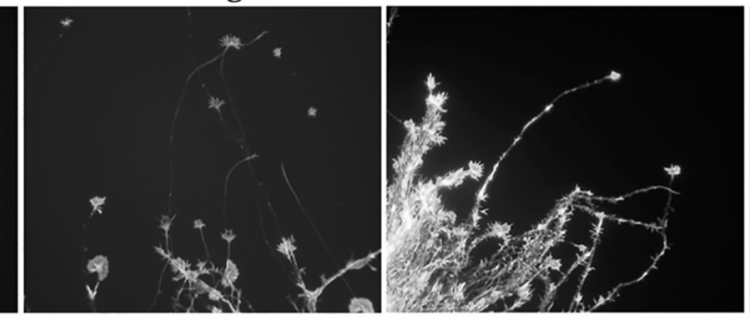

Control/OMgp

s-LOTUS/PBS

s-LOTUS/Nogo66

s-LOTUS/MAG
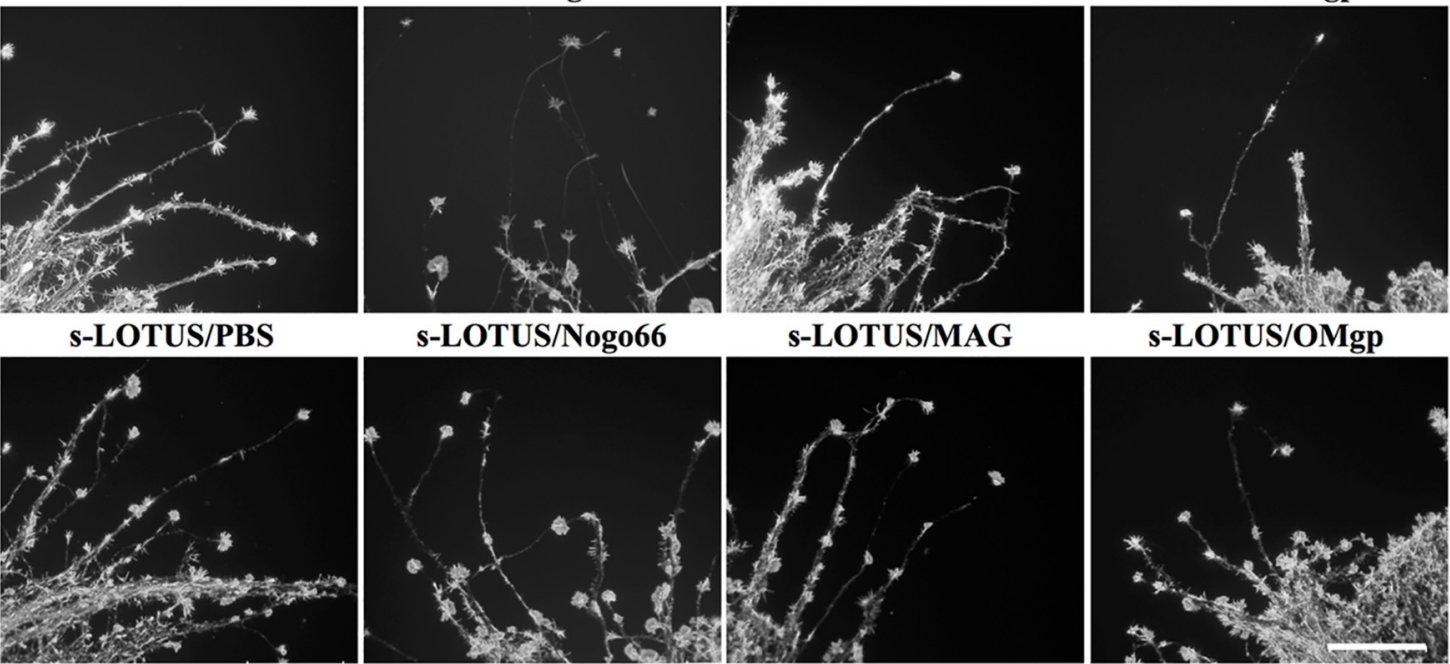

s-LOTUS/OMgp

C

N.S.

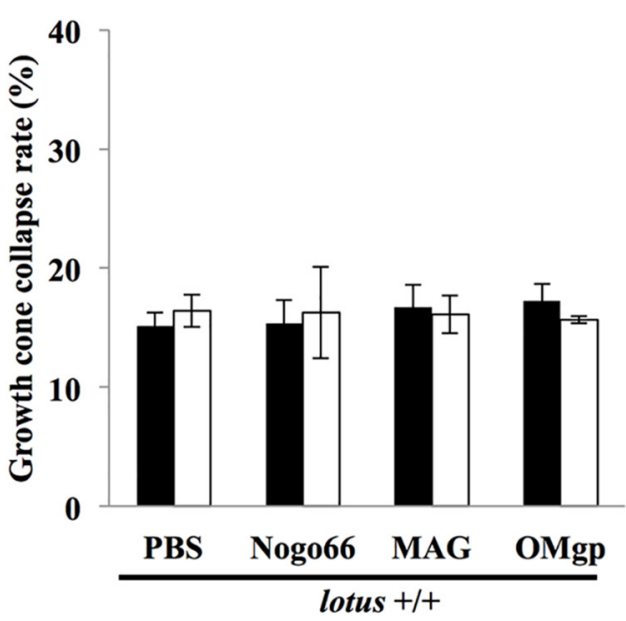

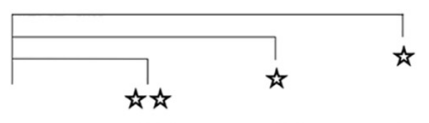

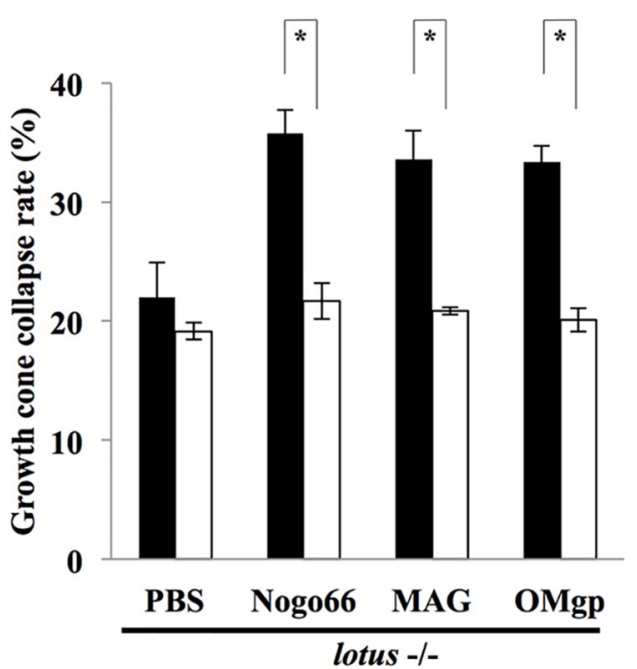

Figure 7. S-LOTUS compensates for the blockade of MAl-induced growth cone collapse by the endogenous function of LOTUS in OB neurons from lotus-KO mice. A, Representative images of colocalization of treated SBP-Fc-LOTUS and endogenous $\mathrm{p} 75^{\mathrm{NTR}}$ in growth cones of OB neurons. Scale bar, $10 \mu \mathrm{m} . \boldsymbol{B}$, Representative images of F-actin staining of growth cones in E13.5 0B neurons. Cultured OB neurons from E13.5 lotus-KO mice were treated with SBP-Fc-LOTUS (1 $\mu \mathrm{m})$ or SBP-Fc (control) and each MAI (Nogo66-Fc: $200 \mathrm{~nm}$; MAG-Fc: 20 nm; OMgp-10His: 50 nM). C, Left, Quantitative analysis of growth cone collapse in $0 B$ neurons from WT mice. Right, Quantitative analysis of growth cone collapse in $B$. Filled bars indicate the collapse rates of growth cones without SBP-Fc-LOTUS treatment and open bars indicate the collapse rates of growth cones with SBP-Fc-LOTUS treatment. Values are expressed as the mean \pm SEM $(n=4)$. NS, Not significant. ${ }^{*} p<0.05$ : one-way ANOVA (Tukey-Kramer), 2 is $p 0.01$ versus control, $\approx p<0.05$ versus control: one-way ANOVA (Dunnett). 
A

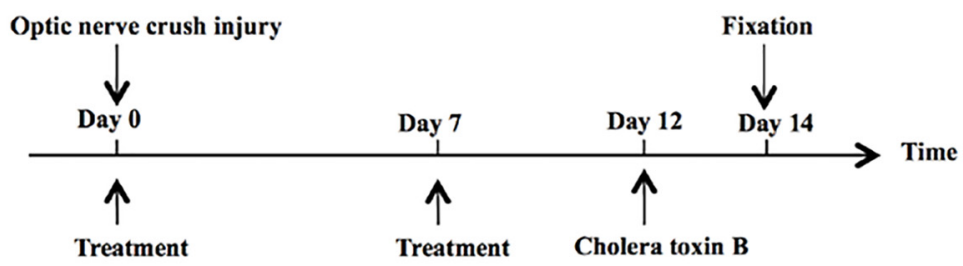

B

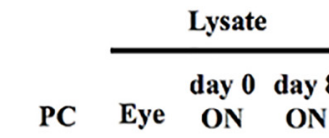

Anti-SBP

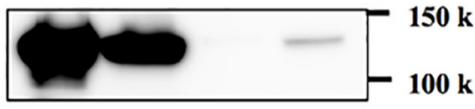

Anti-TUJ 1

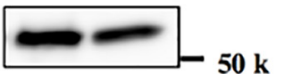

C

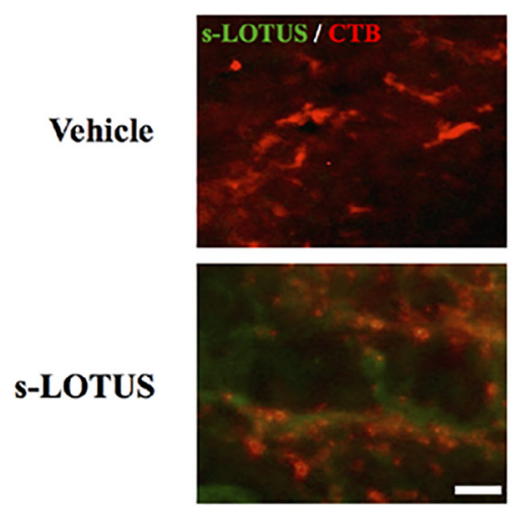

D

Control

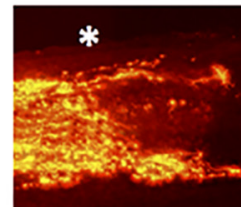

s-LOTUS

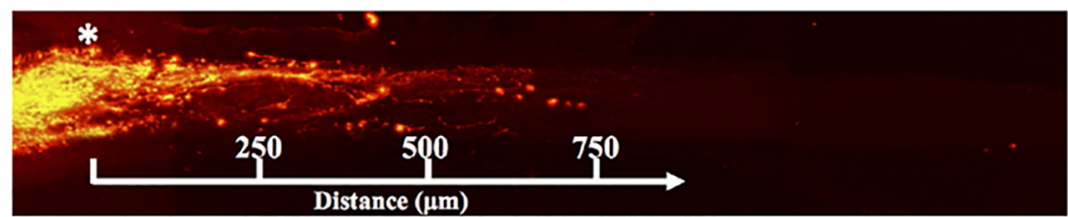

E

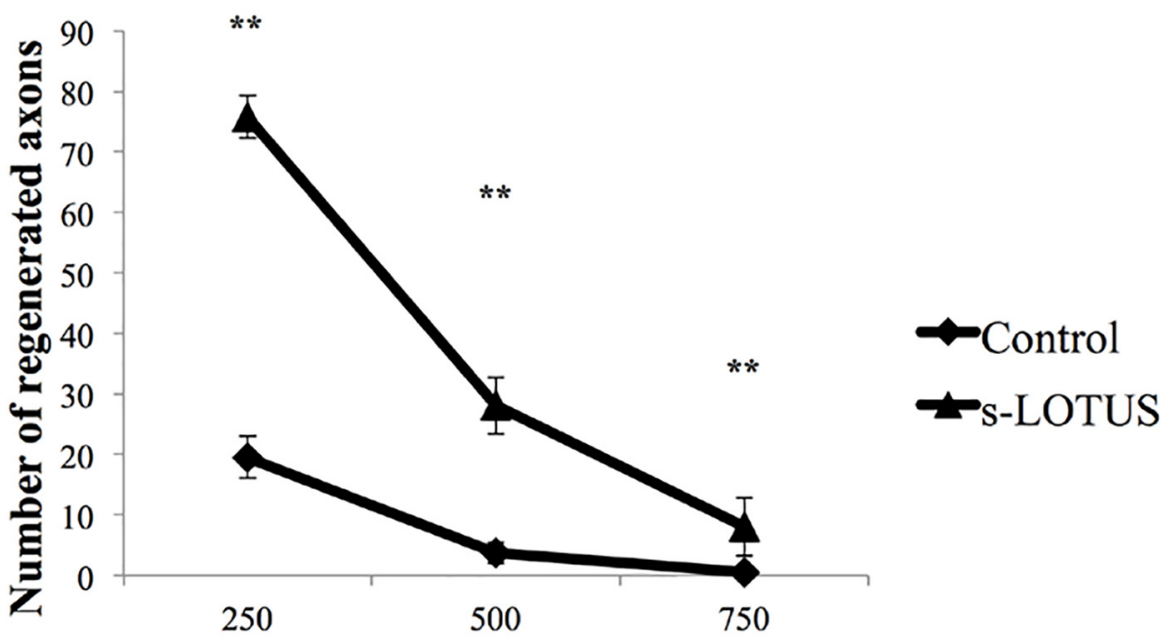

Distance from injury site $(\mu \mathrm{m})$

Figure 8. S-LOTUS promotes axonal regeneration after optic nerve crush injury in mice. $A$, Time course of the optic nerve crush injury experiment. SBP-Fc-LOTUS or SBP-Fc (control) was injected intravitreously twice after injury (day 0 and 7). Thereafter, (TB was injected (day 12) and the animal was perfused (day 14). B, Representative images of Western blotting for detection of s-LOTUS in the crushed optic nerve. TUJ 1, a neuronal marker, was used as a loading control. C, Representative images of immunocytochemistry for detection of s-LOTUS after injection of s-LOTUS (bottom) and vehicle control reagent (top) in the crushed optic nerve. Immunodeposits are indicated in green (s-LOTUS) and red (CTB). Scale bar, $10 \mu$ m. $D$, Representative images of optic nerves showing CTB-labeled RGC axons $14 \mathrm{~d}$ after injury from mice injected with control (top) or s-LOTUS (bottom). Asterisk indicates the injury site and the number indicates the distance from the injury site. $\boldsymbol{E}$, Quantitative analysis of the number of visualized axons at each point observed in all of the optic sections captured by confocal stacks. Values are expressed as the mean \pm SEM $(n=6)$. ${ }^{* *} p<$ 0.01 versus control; two-way ANOVA followed by post hoc Tukey analysis. 
collapsed when they were treated with each of the MAIs (Sato et al., 2011; Kurihara et al., 2014). These previous results suggest that endogenous LOTUS expressed on the growth cone inhibited NgR1-mediated signaling. To determine whether exogenously applied s-LOTUS compensates for the function of endogenous LOTUS in primary neurons, we performed a growth cone collapse assay in $\mathrm{OB}$ neurons from E13.5 lotus-KO mice. We confirmed that applied s-LOTUS bound and colocalized to endogenous p $75^{\text {NTR }}$ on the membranous surface of growth cones and neurite shafts of cultured $\mathrm{OB}$ neurons (Figure $7 A$ ). In $\mathrm{OB}$ neurons from WT mice, treatment with s-LOTUS $(1 \mu \mathrm{M})$ did not affect MAIinduced growth cone collapse due to endogenous expression of LOTUS in these neurons. However, in $\mathrm{OB}$ neurons from lotus-KO mice, treatment with s-LOTUS $(1 \mu \mathrm{M})$ alone had no effect on growth cone collapse, whereas treatment with s-LOTUS $(1 \mu \mathrm{M})$ significantly decreased MAI-induced growth cone collapse to its control level (Fig. $7 B, C$ ). These results suggest that therapeutic treatment with s-LOTUS compensates for the blockade of MAI-induced growth cone collapse by endogenous LOTUS.
A

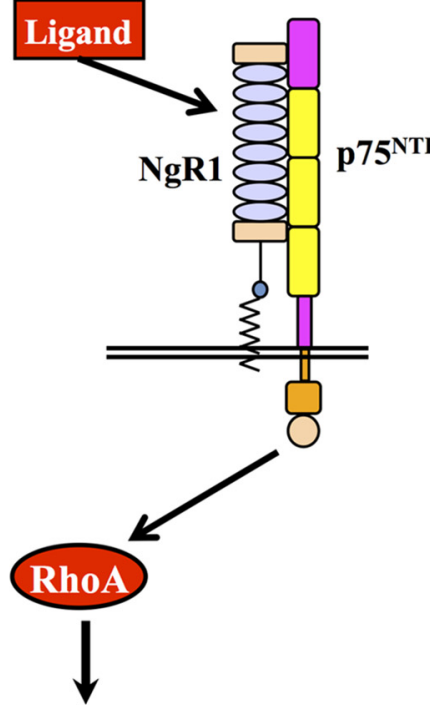

Growth cone collapse

Neurite outgrowth inhibition
B

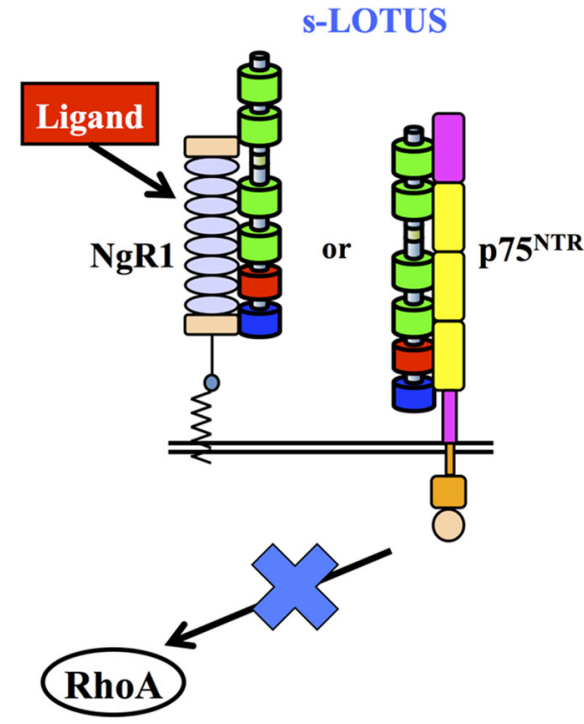

Figure 9. Schematic model of the molecular mechanism of s-LOTUS. $A$, Ligand binding to NgR1 strengthens the interaction between $\mathrm{NgR} 1$ and p $75^{\mathrm{NTR}}$, enhances RhoA activation, and induces signal transduction, which results in growth cone collapse and neurite outgrowth inhibition. $B$, s-LOTUS interferes with the binding of $\mathrm{NgR} 1$ to $\mathrm{p} 75^{\mathrm{NTR}}$ by binding to $\mathrm{NgR} 1$ or $\mathrm{p} 75^{\mathrm{NTR}}$ and thereby inhibits NgR1 ligand-induced signal transduction, resulting in the suppression of growth cone collapse and neurite outgrowth inhibition.

\section{s-LOTUS promotes axonal regeneration in vivo}

Previous reports demonstrate that both p $75^{\text {NTR }}$ (Fujita et al., 2011) and NgR1 (Fischer et al., 2004) prevent axonal regeneration of retinal ganglion cells and that counteracting these molecules or inhibiting the signal pathway of NgR1 enhances axonal extension (Pernet et al., 2013). To assess the relevance of our data in vitro, we investigated whether s-LOTUS can promote axonal regeneration in optic nerve crush injury. We injected $2 \mu \mathrm{l}$ of SBP-Fc-LOTUS $(10 \mu \mathrm{M})$ or control protein (SBP-Fc) intravitreously after crush injury and on POD 7 and injected $2 \mu \mathrm{l}$ of CTB on POD 12 to visualize regenerated axons. We killed the animals on POD 14 and counted the number of axons distal to the injury site (Fig. 8A). We confirmed that intravitreously applied s-LOTUS was detected in the optic nerve around the injury site, suggesting that s-LOTUS may have diffused through the interstitial space along the fibers of retinal ganglion cells (Fig. $8 B, C$ ). We found that significantly more CTB-positive axons were observed in s-LOTUS-treated mice than in control-treated mice (Fig. 8D,E). These results suggest that s-LOTUS can potentially affect the axonal regeneration of retinal ganglion cells after injury in mice.

\section{Discussion}

Our present study showed that s-LOTUS binds to both $\mathrm{p} 75^{\mathrm{NTR}}$ and NgR1 and interferes with the molecular interaction between p $75^{\text {NTR }}$ and NgR1, resulting in the suppression of MAI-induced RhoA activation, growth cone collapse, and neurite outgrowth inhibition in vitro. Moreover, s-LOTUS has a promoting effect on axonal regeneration after injury in vivo.

It is surprising that s-LOTUS did not block ligand binding to $\mathrm{NgR} 1$, in contrast to the membrane-bound form of LOTUS, which blocks ligand binding to NgR1 (Sato et al., 2011; Kurihara et al., 2014). We speculate that the lack of an inhibitory effect of s-LOTUS on ligand binding to NgR1 may be attributed to a different type of binding to $\mathrm{NgR} 1$, such as trans-type versus the cis-type of the membrane-bound form of LOTUS. Further structural investigations are crucial for the clarification of how the membrane-bound form of LOTUS blocks ligand binding to NgR1.

In our study, s-LOTUS and the membrane-bound form of LOTUS bound to p $75^{\text {NTR }}$ (Fig. $1 A-F$ ) and inhibited the interaction of NgR1 with p75 ${ }^{\text {NTR }}$ (Fig. $3 A-E$ ). Moreover, s-LOTUS suppressed MAI-induced growth cone collapse and neurite outgrowth inhibition (Figs. 5, 6, 7; Sato et al., 2011; Kurihara et al., 2014). These results indicate that both the membrane-bound form of LOTUS and s-LOTUS suppress NgR1-mediated axon growth inhibition by preventing NgR1 from binding to $\mathrm{p} 75^{\mathrm{NTR}}$ (Fig. 9). Regarding the molecular mechanism by which LOTUS inhibits the interaction between $\mathrm{p} 75^{\mathrm{NTR}}$ and $\mathrm{NgR} 1$, we hypothesize the following possibilities: first, LOTUS may bind to p75 NTR or NgR1 and change the conformation of $\mathrm{p} 75^{\mathrm{NTR}}$ or NgR1, resulting in a decrease in the binding affinity of $\mathrm{p} 75^{\mathrm{NTR}}$ for NgR1. Second, LOTUS may disturb the approach of $\mathrm{p} 75^{\mathrm{NTR}}$ to NgR1 by binding to $\mathrm{NgR} 1$ at a $\mathrm{p} 75^{\mathrm{NTR}}$-binding site, which includes an $\mathrm{N}$-terminal region, eight leucine-rich repeats, a C-terminal region, and a stalk region in NgR1 (Wang et al., 2002a). This last hypothesis is supported by our findings that LOTUS decreased the NgR1 detection level coprecipitated with $\mathrm{p} 75^{\mathrm{NTR}}$ and the interaction of LOTUS with NgR1 bound to $\mathrm{p} 75^{\mathrm{NTR}}$ was not detected (Fig. 3), although LOTUS also has binding activity on NgR1 (Sato et al., 2011). This suggests that LOTUS cannot bind to both $\mathrm{p} 75^{\mathrm{NTR}}$ and NgR1 proteins simultaneously. In our present study, we therefore hypothesize that molecular interaction of 
s-LOTUS with p $75^{\mathrm{NTR}}$ or NgR1 induces inhibition of NgR1mediated signaling (Fig. 9). However, we could not determine whether simultaneous molecular interactions of s-LOTUS with both $\mathrm{p} 75^{\mathrm{NTR}}$ and $\mathrm{NgR} 1$ are essential for this inhibition or if binding of s-LOTUS to $\mathrm{p} 75^{\mathrm{NTR}}$ alone is sufficient. Further investigations are required to elucidate the molecular binding site in the interactions among LOTUS, NgR1, and $\mathrm{p} 75^{\mathrm{NTR}}$.

The inhibition of $\mathrm{p} 75^{\mathrm{NTR}}, \mathrm{NgR} 1$, or its signaling pathway improves the regenerative capacity of damaged axons in retinal ganglion cells in an animal model of optic nerve crush injury (Pernet et al., 2013). However, some reports show that a single administration of an inhibitor of NgR1 signaling does not enhance neuronal regeneration in this model and that the synergism with macrophage-derived factors is required to allow retinal ganglion cells to be in an active growth state (Fischer et al., 2004; Dickendesher et al., 2012; Pernet et al., 2013). In our present study, s-LOTUS enhanced neuronal regeneration after optic nerve crush injury. Because NgR1 is expressed in macrophages and the expression increases when a peripheral nerve is injured (Fry et al., 2007), intravitreously injected s-LOTUS may also interact with $\mathrm{NgR} 1$ expressed on the cell surface of macrophages around the injured optic nerve to affect macrophages, leading to an improvement in the regenerative capability of damaged optic axons. There is a possibility that s-LOTUS may function not only in the inhibition of NgR1-mediated signaling, but may also exert an immunological effect through interactions with $\mathrm{NgR} 1$ on macrophages.

We have reported that s-LOTUS is detected in human CSF and that its concentration declines according to the disease activity of patients with multiple sclerosis (Takahashi et al., 2015). In the present study, we showed that exogenously added s-LOTUS suppresses MAI-induced RhoA activation, growth cone collapse, and neurite outgrowth inhibition in vitro and promotes axonal regeneration after optic nerve injury in vivo. Our data suggest that the enhancement of both the expression and secretion of LOTUS may also be useful for the promotion of axon regeneration, although the mechanism by which the expression level of LOTUS is regulated and how the membrane-bound form of LOTUS is cleaved remain unknown.

p $75^{\text {NTR }}$ is a receptor for neurotrophins such as NGF and brain-derived neurotrophic factor (Meeker and Williams, 2015). In the present study, we identified $\mathrm{p} 75^{\mathrm{NTR}}$ as a novel binding partner of LOTUS. We demonstrated that the administration of s-LOTUS regenerates injured axons after optic nerve injury. This finding raises the possibility that the promoting effect of s-LOTUS on axonal regeneration may be ascribed to, not only the inhibition of NgR1-mediated signaling, but also the stimulation of neurite outgrowth activity through $\mathrm{p} 75^{\mathrm{NTR}}$. In addition, $\mathrm{p} 75^{\mathrm{NTR}}$ is also involved in proliferation, differentiation, and regeneration in neural progenitor cells as a coreceptor of several receptors such as the tropomyosin receptor kinase family, sortilin receptor, and paired Ig-like receptor B (Fujita et al., 2011; Meeker and Williams, 2015). It is interesting to consider that LOTUS may also regulate neuronal development, survival, and regeneration by binding to $\mathrm{p} 75^{\mathrm{NTR}}$.

In conclusion, this study shows that s-LOTUS interacts with $\mathrm{NgR} 1$ or $\mathrm{p} 75^{\mathrm{NTR}}$, thereby interfering with the interaction between NgR1 and $\mathrm{p} 75^{\mathrm{NTR}}$, and eventually inhibits NgR1-mediated signaling (Fig. 9B). This finding suggests that s-LOTUS may be a potential therapeutic agent for regeneration after CNS injury.

\section{References}

Barton WA, Liu BP, Tzvetkova D, Jeffrey PD, Fournier AE, Sah D, Cate R, Strittmatter SM, Nikolov DB (2003) Structure and axon outgrowth in- hibitor binding of the nogo-66 receptor and related proteins. EMBO J 22:3291-3302. CrossRef Medline

Bregman BS, Kunkel-Bagden E, Schnell L, Dai HN, Gao D, Schwab ME (1995) Recovery from spinal cord injury mediated by antibodies to neurite growth inhibitors. Nature 378:498-501. CrossRef Medline

Dickendesher TL, Baldwin KT, Mironova YA, Koriyama Y, Raiker SJ, Askew KL, Wood A, Geoffroy CG, Zheng B, Liepmann CD, Katagiri Y, Benowitz LI, Geller HM, Giger RJ (2012) NgR1 and NgR3 are receptors for chondroitin sulfate proteoglycans. Nat Neurosci 15:703-712. CrossRef Medline

Fischer D, He Z, Benowitz LI (2004) Counteracting the nogo receptor enhances optic nerve regeneration if retinal ganglion cells are in an active growth state. J Neurosci 24:1646-1651. CrossRef Medline

Fournier AE, GrandPre T, Strittmatter SM (2001) Identification of a receptor mediating nogo-66 inhibition of axonal regeneration. Nature 409: 341-346. CrossRef Medline

Fournier AE, Takizawa BT, Strittmatter SM (2003) Rho kinase inhibition enhances axonal regeneration in the injured CNS. J Neurosci 23:14161423. Medline

Fry EJ, Ho C, David S (2007) A role for nogo receptor in macrophage clearance from injured peripheral nerve. Neuron 53:649-662. CrossRef Medline

Fujita Y, Takashima R, Endo S, Takai T, Yamashita T (2011) The p75 receptor mediates axon growth inhibition through an association with PIR-B. Cell Death Dis 2:e198. CrossRef Medline

GrandPré T, Nakamura F, Vartanian T, Strittmatter SM (2000) Identification of the nogo inhibitor of axon regeneration as a reticulon protein. Nature 403:439-444. CrossRef Medline

GrandPré T, Li S, Strittmatter SM (2002) Nogo-66 receptor antagonist peptide promotes axonal regeneration. Nature 417:547-551. CrossRef Medline

Kapfhammer JP, Xu H, Raper JA (2007) The detection and quantification of growth cone collapsing activities. Nat Protoc 2:2005-2011. CrossRef Medline

Kurihara Y, Iketani M, Ito H, Nishiyama K, Sakakibara Y, Goshima Y, Takei K (2014) LOTUS suppresses axon growth inhibition by blocking interaction between nogo receptor-1 and all four types of its ligand. Mol Cell Neurosci 61:211-218. CrossRef Medline

Li S, Liu BP, Budel S, Li M, Ji B, Walus L, Li W, Jirik A, Rabacchi S, Choi E, Worley D, Sah DW, Pepinsky B, Lee D, Relton J, Strittmatter SM (2004) Blockade of nogo-66, myelin-associated glycoprotein, and oligodendrocyte myelin glycoprotein by soluble nogo-66 receptor promotes axonal sprouting and recovery after spinal injury. J Neurosci 24:10511-10520. CrossRef Medline

Liu BP, Fournier A, GrandPré T, Strittmatter SM (2002) Myelin-associated glycoprotein as a functional ligand for the nogo-66 receptor. Science 297: 1190-1193. CrossRef Medline

Meeker RB, Williams KS (2015) The p75 neurotrophin receptor: at the crossroad of neural repair and death. Neural Regen Res 10:721-725. CrossRef Medline

Mi S, Lee X, Shao Z, Thill G, Ji B, Relton J, Levesque M, Allaire N, Perrin S, Sands B, Crowell T, Cate RL, McCoy JM, Pepinsky RB (2004) LINGO-1 is a component of the nogo-66 receptor/p75 signaling complex. Nat Neurosci 7:221-228. CrossRef Medline

Niclou SP, Ehlert EM, Verhaagen J (2006) Chemorepellent axon guidance molecules in spinal cord injury. J Neurotrauma 23:409-421. CrossRef Medline

Pernet V, Joly S, Jordi N, Dalkara D, Guzik-Kornacka A, Flannery JG, Schwab ME (2013) Misguidance and modulation of axonal regeneration by Stat 3 and Rho/ROCK signaling in the transparent optic nerve. Cell Death Dis 4:e734. CrossRef Medline

Sato Y, Iketani M, Kurihara Y, Yamaguchi M, Yamashita N, Nakamura F, Arie Y, Kawasaki T, Hirata T, Abe T, Kiyonari H, Strittmatter SM, Goshima Y, Takei K (2011) Cartilage acidic protein-1B (LOTUS), an endogenous nogo receptor antagonist for axon tract formation. Science 333:769-773. CrossRef Medline

Schwab ME (2010) Functions of nogo proteins and their receptors in the nervous system. Nat Rev Neurosci 11:799-811. CrossRef Medline

Smith PD, Sun F, Park KK, Cai B, Wang C, Kuwako K, Martinez-Carrasco I, Connolly L, He Z (2009) SOCS3 deletion promotes optic nerve regeneration in vivo. Neuron 64:617-623. CrossRef Medline

Steck E, Bräun J, Pelttari K, Kadel S, Kalbacher H, Richter W (2007) Chondrocyte secreted CRTAC1: a glycosylated extracellular matrix molecule of human articular cartilage. Matrix Biol 26:30-41. CrossRef Medline 
Takahashi K, Kurihara Y, Suzuki Y, Goshima Y, Tanaka F, Takei K (2015) Association of cerebrospinal fluid levels of lateral olfactory tract usher substance (LOTUS) with disease activity in multiple sclerosis. JAMA Neurol 72:176-179. CrossRef Medline

van Erp S, van den Heuvel DM, Fujita Y, Robinson RA, Hellemons AJ, Adolfs Y, Van Battum EY, Blokhuis AM, Kuijpers M, Demmers JA, Hedman H, Hoogenraad CC, Siebold C, Yamashita T, Pasterkamp RJ (2015) Lrig2 negatively regulates ectodomain shedding of axon guidance receptors by ADAM proteases. Dev Cell 35:537-552. CrossRef Medline

Wang KC, Kim JA, Sivasankaran R, Segal R, He Z (2002a) P75 interacts with the Nogo receptor as a co-receptor for Nogo, MAG and OMgp. Nature 420:74-78. CrossRef Medline
Wang KC, Koprivica V, Kim JA, Sivasankaran R, Guo Y, Neve RL, He Z (2002b) Oligodendrocyte-myelin glycoprotein is a nogo receptor ligand that inhibits neurite outgrowth. Nature 417:941-944. CrossRef Medline

Yamashita T, Tohyama M (2003) The p75 receptor acts as a displacement factor that releases rho from rho-GDI. Nat Neurosci 6:461-467. CrossRef Medline

Yiu G, He Z (2006) Glial inhibition of CNS axon regeneration. Nat Rev Neurosci 7:617-627. CrossRef Medline

Zhang L, Zheng S, Wu H, Wu Y, Liu S, Fan M, Zhang J (2009) Identification of BLyS (B lymphocyte stimulator), a non-myelin-associated protein, as a functional ligand for nogo-66 receptor. J Neurosci 29:6348-6352. CrossRef Medline 